\title{
Assessment of the Biological Activities of Egyptian Purslane (Portulaca oleracea) Extract after Incorporating Metal Nanoparticles, in Vitro and in Vivo Study
}

\author{
Wael Mahmoud Aboulthana ${ }^{1 *}$, Nagwa Ibrahim Omar', Enas Ahmed Hasan², \\ Kawkab A. Ahmed ${ }^{3}$, Ahmed Mahmoud Youssef ${ }^{4}$
}

\begin{abstract}
Objective: Egyptian Purslane (Portulaca oleracea) is rich in omega-3 fatty acids and a wide range of vitamins and phyto-constituents that were absorbed slowly due to their high molecular weights. Therefore, this study was designed to accelerate the absorption of these phyto-constituents and hence increase their bioavailability by incorporating silver (Ag-NPs) and zinc oxide nanoparticles (ZnO-NPs) due to their impressive properties. Methods: The major phytoconstituents and different biological activities were quantified in aqueous extract before and after incorporating metal nanoparticles (M-NPs). The efficiency of ZnO-P. nano-extract was studied on cell cycle and apoptosis of human hepatocellular carcinoma (HEPG-2) cells. Then, both Ag- and ZnO-P. nano-extracts were studied against hepatic fibrosis induced by thioacetamide (TAA) in rats through undergoing different hematological and biochemical measurements in addition to the histopathological examination in hepatic tissues compared to the extract itself. Results: The ZnO-P. nano-extract showed significantly $(\mathrm{P}<0.05)$ higher antioxidant and scavenging activity due to the existence of higher total polyphenolic content. Also, it exhibited a significantly $(\mathrm{P}<0.05)$ higher inhibitory effect on acetyl cholinesterase (AChE) activity and higher cytotoxic activity against HEPG-2 cells. Therefore, $\mathrm{ZnO}$-P. nano-extract was studied against the cell cycle and apoptosis of HEPG-2 cells compared to the extract itself. It was found that ZnO-P. nano-extract was safer than Ag-P. nano-extract. Both Ag- and ZnO- P. nano-extracts were studied against the hepatic fibrosis induced by thioacetamide (TAA) compared to the native extract. It was noticed that $\mathrm{ZnO}-\mathrm{P}$. nano-extract exhibited an ameliorative effect against hepatic fibrosis by decreasing levels of inflammatory and fibrotic markers significantly $(\mathrm{P}<0.05)$ more than Ag-P. nano-extract. Furthermore, it improved the antioxidant status of the hepatic tissue in addition to restoring the histopathological architecture of liver tissue. Conclusion: ZnO-P. nano-extract showed higher in vitro and in vivo biological activities than Ag-P. nano-extract and native P. extract itself.
\end{abstract}

Keywords: Portulaca oleracea- biological activity- silver nanoparticles- zinc oxide nanoparticles- green nanotechnology

Asian Pac J Cancer Prev, 23 (1), 287-310

\section{Introduction}

Portulaca oleracea belongs to the Family portulacaceae and the genus Portulaca. Therefore, it is commonly called Purslane (Azuka et al., 2014). It was mentioned in Egyptian texts from the time of the Pharaohs that Purslane was used as a nutritious vegetable because it is richer in omega-3 fatty acids and wide range of vitamins like vitamin $\mathrm{A}, \mathrm{B}, \mathrm{C}$ and carotenoids in addition to beneficial minerals like magnesium, calcium, potassium, and iron than other vegetables consumed by a human being (Uddin et al., 2014). Also, two types of betalain alkaloid pigments with antioxidant and antimutagenic activities were detected in the P. extract (Sudhakar et al., 2010).
It was used widely in Chinese medicine as antifertility, anti-diabetic, antifungal and anti-inflammatory in addition to the wound healing properties and the protective effect against oxidative stress caused by vitamin A deficiency (Gong et al., 2009). Moreover, it was used for dysentery treatment beside its ability to increase uterine contraction (Arruda et al., 2004). It was documented that Purslane exhibited hepatoprotective effects against the hepatotoxicity and liver fibrosis induced by numerous toxins and it is able to restore all the disturbed biochemical parameters to normal values (Anusha et al., 2011; Ali et al., 2011). In 2019, Seif et al. emphasized that the ethanolic Purslane extract exhibited hepato-and renal-protective effects against cadmium toxicity. Purslane extract is rich 
in various active phyto-constituents with high molecular weights and absorbed slowly. This leads to decreasing their efficacy and bioavailability. Nanotechnology was being applied to integrate the efficiency of the medicinal plant extracts to increase their bioavailability, reduce their toxicity and avoid absorption problems. So that, the activity and therapeutic effect of extracts increased by incorporating the nanoparticles (NPs) (Mamillapalli et al., 2016 ; Abdel-Halim et al., 2020). Synthesis of the nanomaterials by green nanotechnology was considered as an environmentally-friendly (nontoxic) method more than the other chemical and physical methods. The metal nanoparticles (M-NPs) are purely made of the metals' precursors that possess unique optoelectrical properties (Prow et al., 2011; Dreaden et al., 2012). The sizes and shapes of metallic nanomaterials are based mainly on their physical, chemical and optical properties (Lee et al., 2018). They were biosynthesized successfully using plant-based materials as reducing agents (Fatimah, 2016). The polyphenolic compounds and flavenoids are the most common phyto-constituents that are used as reducing agents during M-NPs biosynthesis (Sahaa et al., 2008). Size, morphological shape, distribution and surface properties of the M-NPs affected strongly their physical, catalytic and optical properties (El-Nour et al., 2010).

Silver nanoparticles (Ag-NPs) are characterized by their chemical and biological properties in addition to their physical superiority that stems mainly from the shape, size, crystallinity, structure, and composition of the Ag-NPs more than their bulk forms (Syafiuddin et al., 2017). Zinc oxide nanoparticles (ZnO-NPs) had attracted great interest among scientists among the M-NPs due to their impressive properties including the large binding energy, wide band gap and high piezoelectric property (Dagdeviren et al., 2013). Chemically, the presence of -OH groups on the surface of the ZnO-NPs permit them to dissolve slowly in both acidic and basic conditions. Based on this characteristic that enables $\mathrm{ZnO}-\mathrm{NPs}$ to dissolve in the tumor cells and tumor microenvironment, they exhibited a wide range of biomedical applications as anti-angiogenesis, antiplatelet, anti-inflammatory, and anticancer agents in addition to drug and gene delivery (Bisht and Rayamajhi, 2016 ; Sonia et al., 2017).

Liver fibrosis is a chronic wound healing after liver damage. It is major health distress that consequently leads to liver cirrhosis, liver cancer and hence causes significant morbidity and mortality (Stickel and Schuppan, 2007). It is complex pathogenesis induced by amendments of the hepatic extracellular matrix (ECM) qualitatively and quantitatively. There is no standard treatment for activation of the hepatic stellate cells (HSCs) that is considered the most common cause of liver fibrosis (Greenwel et al., 2000). Oxidative stress is one of the key factors that induce inflammation by activating the HSCs involved in ECM deposition (Reeves and Friedman, 2002). Thioacetamide (TAA) belongs to the hepatotoxins that have been utilized in a multiplicity of studies due to their ability to induce liver fibrosis in rodents with metabolic and histopathological alterations commonly similar to those detected in livers of humans afflicted to be used as an ideal model for studying the potential anti-fibrotic drugs (Laleman et al., 2006). This study is concerned with demonstrating the possible hepatoprotective effect of $P$. extract incorporated with Ag- and ZnO-NPs and ingested orally in attenuating liver fibrosis induced by TAA in rat models.

\section{Materials and Methods}

\section{Preparation of aqueous Purslane extract}

Fresh Purslane leaves were collected and thoroughly washed by double deionized water to remove surface impurities then dried at ambient temperature $\left(25^{\circ} \mathrm{C}\right)$. The dried plant material was weighed, chopped and crushed in an electric blender into powder. The air dried plant material (50 gm) was soaked in $500 \mathrm{ml}$ pure water and heated under reflux for $60 \mathrm{~min}$ then filtered. The filtrate was lyophilized and the crude yield was approximately $32 \%$ (w/w) (Eidi et al., 2015).

\section{Preparation of metal Purslane nano-extract}

In order to prepare Ag-NPs and $\mathrm{ZnO}-\mathrm{NPs}$ with optimum particle size and yield, several attempts were performed to obtain an easy method by using the plant extract as a reducing agent during the biosynthesis process. For the preparation of silver Purslane nano-extract, the Ag-NPs were prepared by reducing silver nitrate $\left(\mathrm{AgNO}_{3}\right)$ in the existence of Purslane extract as suggested by Aboulthana et al., (2019) and Shousha et al., (2019). The optimum method was exploited to incorporate Ag-NPs (with required yield and particle size) into the plant extract. For the preparation of the $\mathrm{ZnO}$-Purslane nano-extract, the ZnO-NPs were synthesized by a sol-gel method suggested by Bao et al., (2012) with some modifications. The plant extract was added into zinc acetate solution till obtaining the white precipitate that dried and converted into powder to be ready for characterization.

\section{Characterization of the biosynthesized metal nanoparticles}

The Ag-NPs and ZnO-NPs spectra were assayed by Shimadzu UV-VIS recording spectrophotometer UV-240 at $\lambda 200-800 \mathrm{~nm}$ after diluting the samples (10-fold) with deionized water. The crystalline nature and grain size were analyzed by a Philips X-ray diffractometer (XRD) (PW 1930 generator, PW 1820 goniometer) equipped with $\mathrm{Cu} \mathrm{K \alpha}$ radiation as an X-ray source $(45 \mathrm{kV}, 40 \mathrm{~mA}$, with $\lambda=0.15418 \mathrm{~nm})$ at a temperature of $25-28^{\circ} \mathrm{C}$. The analysis scans were carried out during run in $2 \theta$ range of 5 to $80^{\circ}$ with a step time of $1 \mathrm{~s}$ and step size of 0.02 . The morphological shape and size of the synthesized M-NPs were determined at a high resolution level (200 KV) using a Transmission Electron Microscope (TEM) (model JEM-1230, Japan) operated at an accelerating voltage of $120 \mathrm{kV}$, with a maximum magnification of $600 \mathrm{X} 103$ and a resolution until $0.2 \mathrm{~nm}$. The average hydrodynamic size of the synthesized M-NPs was determined by dynamic light scattering (DLS) (Malvern Zetasizer Nano ZS, Malvern Instruments Ltd., Malvern, United Kingdom) at room temperature with a detection angle of $90^{\circ}$ after diluting the samples with double distilled water prior to analysis (Murdock et al., 2008). 
In vitro study on aqueous Purslane extract before and after incorporating metal nanoparticles

Total polyphenolic compounds

The concentration of the total polyphenols was quantified in the aqueous Purslane extract and its metal nano-extracts as mg gallic acid/100 gm using Folin Ciocalteu reagent according to the method suggested by Singleton and Rossi (1965).

\section{Total tannins content}

Contents of the total condensed tannins were determined using tannic acid as a reference compound based on the method described by Broadhurst and jones (1978).

\section{Total antioxidant capacity}

Total antioxidant capacity (TAC) was quantified in the native and metal nano-extracts as mg gallic acid equivalent per gram dry weight according to the method suggested by Prieto et al., (1999).

\section{Iron reducing power}

Total iron reducing power was assessed using ascorbic acid as standard according to the method described by Oyaizu (1986).

\section{Free radical scavenging activities}

The scavenging activities were assessed in the Purslane extract and its metal nano-extract by measuring their ability to scavenge the free radicals.

\section{DPPH radical-scavenging activity}

The 1,1-Diphenyl-2-picryl-hydrazyl (DPPH) radical scavenging activity was assayed by calculating the percent of the DPPH free radical inhibition (\%) and the median inhibitory concentration $\left(\mathrm{IC}_{50}\right)$ according to the method suggested by Rahman et al., (2015).

\section{ABTS radical scavenging assay}

The 2,2'-azinobis-(3-ethylbenzothiazoline-6-sulfonic acid) (ABTS) assay was carried out using ascorbic acid as standard based on the method described by Arnao et al., (2001) with some modifications.

\section{Alpha-amylase inhibitory assay}

The $\alpha$-amylase inhibitory assay of the plant extract and its metal nano-extracts was carried out using acarbose as an standard drug for calculating the percentage of $\alpha$-amylase inhibition using the 3.5-dinitrosalicylic acid (DNSA) method (Wickramaratne et al., 2016).

\section{Acetyl cholinesterase (AChE) enzyme activity}

The AChE activity was measured for calculating the enzyme inhibition (\%) using a spectrophotometer based on Ellman's method (Ellman et al., 1961).

\section{Cytotoxic activity}

Cytotoxic activity tests (In vitro bioassay on human hepatocellular (HEPG-2) and colon carcinoma (CACO2 ) cell lines) were conducted and determined based on the 3-(4,5-dimethythiazol-2-yl)-2,5-diphenyl tetrazolium bromide (MTT) assay suggested by Vichai and Kirtikara (2006). The optical density (OD) was determined at $570 \mathrm{~nm}$ by a microplate ELISA reader. The percent of cell-growth inhibition (\%) and median inhibitory concentration $\left(\mathrm{IC}_{50}\right)$ were calculated using $\mathrm{IC}_{50}$ calculation software.

\section{DNA content analysis}

The HEGP-2 cells $\left(3 \times 10^{5} /\right.$ well $)$ were seeded into 6 -well plates, cultured overnight, and treated with native $\mathrm{P}$. extract and its $\mathrm{ZnO}$ nano-extract for $24 \mathrm{hrs}$. The cells were fixed in $75 \%$ ethanol at $-4^{\circ} \mathrm{C}$ overnight then incubated with $50 \mathrm{ng} / \mathrm{mL}$ PI staining solution and $0.1 \mathrm{mg} / \mathrm{mL}$ RNase $\mathrm{A}$ in a dark place at room temperature for $15 \mathrm{~min}$. The DNA content of the cells was quantified by flow cytometry (BD FASCCalibur-USA).

\section{Cell apoptosis}

The cell apoptosis was assessed by Annexin V-FITC apoptosis detection kit (Annexin V-FITC-BD Bioscience PharmingenTM, USA). The HEPG- 2 cells $\left(3 \times 10^{6} /\right.$ well $)$ were seeded into 6 -well plates then cultured overnight before the exposure to different concentrations of the extract and its $\mathrm{ZnO}-\mathrm{P}$. nano-extract (50, 100, 150, 200 $\mu \mathrm{g} / \mathrm{ml})$. Furthermore, both the extract and its nano-extract $(100 \mu \mathrm{g} / \mathrm{ml})$ were added to HEPG-2 cells at different times $(24,36,48$, and $48 \mathrm{hrs})$. Cells were collected by cold centrifugation at approximately $300 \mathrm{x}$ g for $10 \mathrm{~min}$ and consequently washed twice and re-suspended in $500 \mu \mathrm{l}$ of cold $(+4 \mathrm{oC}) 1 \mathrm{X}$ PBS buffer then precipitated again by centrifugation. This was followed by the dilution with $10 \mathrm{X}$ Binding Buffer (1:10 dilution) in deionized $\mathrm{H}_{2} \mathrm{O}$ then 100 $\mu \mathrm{l} 1 \mathrm{X}$ Binding Buffer added per sample. Annexin V (100 $\mu \mathrm{l})$ was prepared and incubated with treated cell samples $\left(10^{6} \mathrm{cell} / \mathrm{ml}\right)$. Annexin V-FITC $(5 \mu \mathrm{l})$ and propidium iodide (PI) $(5 \mu \mathrm{l})$ were incubated in the dark for $15 \mathrm{~min}$. at room temperature, then $400 \mu \mathrm{l}$ of $1 \mathrm{X}$ binding buffer was added. The cells were immediately analyzed by flow cytometry (BD FASCCalibur-USA) within one hour for a maximal signal (Koopman et al., 1994).

\section{Extraction of RNA and quantitative RT-PCR}

The HEPG-2 cells were cultured in six-well plates and exposed to the extract and its $\mathrm{ZnO}$ nano-extract $(100 \mu \mathrm{g} / \mathrm{ml})$. After completing the exposure, total RNAs were extracted from treated cells using the RNeasy Mini Kit (Qiagen RNA extraction/BioRad syber green PCR MMX) (Pfaffl, 2001). Expressions of EGFR, Bcl-2 and Casp3 genes were quantified by using $10 \mathrm{ng}$ of the total RNAs from each sample for cDNA synthesis by reverse transcription using the High Capacity cDNA Reverse Transcriptase kit (Applied Biosystems, USA). The cDNA was subsequently amplified with the Syber Green I PCR Master Kit (Fermentas) in a 48-well plate using the Step One instrument (Applied Biosystems, USA), as a following: $10 \mathrm{~min}$ at $95^{\circ} \mathrm{C}$ for enzyme activation followed by 40 cycles of $15 \mathrm{sec}$ at a temperature of $95^{\circ} \mathrm{C}$, $20 \mathrm{sec}$ at $55^{\circ} \mathrm{C}$ and $30 \mathrm{sec}$ at $72^{\circ} \mathrm{C}$ for the amplification step. Changes in each target gene expression were normalized relative to the mean critical threshold (CT) values of GAPDH as a housekeeping gene by the $\Delta \mathrm{Ct}$ 
method. One $\mu$ l of both primers specific for each target gene (EGFR (F: 5'-GACTCCGTCCAGTATTGATCG-3'; B： 5'-GCCCTTCGCACTTCTTACACTT-3'), Bcl2 (F: 5'-TCCCTCGCTGCACAAATACTC-3'; B: 5'-ACGACCCGATGGCCAAGA-3'), Casp3 (F： 5' - TGTTTGTGTGCTTCTGAGCC-3'; B: 5'-CACGCCATGTCATCATCAAC-3') and GAPDH (F： 5'-GAAGGTGAAGGTCGGAGTCA-3'; B: 5'-TTGAGGTCAATGAAGGGGTC-3')) was added. The mRNA levels were quantified using the $2 \Delta \Delta \mathrm{Cq}$ method (Wang et al., 2014). GAPDH was used as the internal control. Experiments for each gene were conducted in triplicate.

\section{Median lethal dose of different extracts (LD50)}

The native Purslane extract and its metal nano-extracts (after incorporating Ag-NPs and ZnO-NPs) were studied separately for evaluating the LD50. One hundred sixty two adult albino mice (weight 20-25 g) were divided into 9 groups (6 mice in each group) for calculating the LD50 of the native Purslane extract, 9 groups for Ag-P. nano-extract and 9 groups for $\mathrm{ZnO}-\mathrm{P}$. nano-extract. The groups were treated orally by stomach tube with rising doses of 500, 1,000, 2,000, 4,000, 6,000, 8,000, 10,000, 12,000 and $14,000 \mathrm{mg} / \mathrm{Kg}$. Mortality was recorded after $24 \mathrm{hrs}$ of oral administration. The LD50 was calculated according to the methods suggested by Paget and Barnes (1964).

\section{Experimental Design}

Animals and Treatments

Healthy forty (40) adult male Sprague Dawley rats with age 2 months old and body weight 120-150 g were obtained from the Animal House Colony, National Research Centre, Giza, Egypt. They were provided with water ad libitum and maintained under normal nutritional and environmental conditions. They were divided randomly into 8 groups ( 5 rats per cage) as the following:

Control group: rats were fed with a normal diet and received tap water for 4 weeks. P. extract treated group: rats were fed with a normal diet associated with administration of native P. extract orally at a dose equivalent to $1 / 20$ of LD50 by stomach tube for 4 weeks. Ag-P. nano-extract treated group: rats were fed with a normal diet associated with administration of silver P. nano-extract orally at a dose equivalent to $1 / 20$ of LD50 by stomach tube for 4 weeks. ZnO-P. nano-extract treated group: rats were fed with a normal diet associated with administration of $\mathrm{ZnO}-\mathrm{P}$. nano-extract orally at a dose equivalent to $1 / 20$ of LD50 by stomach tube for 4 weeks. TAA injected group: Rats were injected by TAA at a dose of $200 \mathrm{mg} / \mathrm{kg}$, i.p. three-time per week for 4 weeks (Algandaby et al., 2017). TAA + P. extract treated group: Rats treated simultaneously with TAA i.p. and treated orally by P. extract for 4 weeks. TAA + Ag-P. nano-extract treated group: Rats treated simultaneously with TAA i.p. and treated orally by Ag-P. nano-extract for 4 weeks. TAA + ZnO-P. nano-extract treated group: Rats treated simultaneously with TAA i.p. and treated orally by $\mathrm{ZnO}-\mathrm{P}$. nano-extract for 4 weeks.
Determination of the changes in body and liver weights

The total body weights of all rats were measured at start and end of the experimental duration using a digital balance. The weight gain was calculated using the formula suggested by Al-Attar (2010). The livers were washed with saline solution and dried between filter papers then weighted. The liver index was calculated using the formula suggested by Al-Attar and Al-Rethea, (2017).

\section{Samples collection}

At end of the experiment, rats were fasted for $18 \mathrm{hrs}$ and sacrificed by cervical dislocation after deep diethyl ether anesthesia. Heparinized blood samples were collected from retro orbital plexus from each rat for the hematological measurements and serum samples were collected for biochemical measurements by centrifuging blood samples for $15 \mathrm{~min}$ at 4,000 rpm. Liver tissues were autopsied and weighted then dissected into two parts, one part was immediately fixed in $10 \%$ formal saline until the histopathological examination and the other part was washed immediately in physiological saline and rapidly frozen in liquid nitrogen then homogenized in Tris- $\mathrm{HCl}$ buffer $(0.01 \mathrm{M}$ and $\mathrm{pH}$ 7.4). The clear supernatants were transferred to new tubes after centrifuging the homogenates at $10,000 \mathrm{rpm}$ for $15 \mathrm{~min}$ then kept at $-20^{\circ} \mathrm{C}$ in clean stoppered vials to be used for biochemical assays.

\section{Hematological and biochemical measurements}

The hematological measurements including red blood cells (RBCs), hemoglobin (HB), hematocrit (HCT), corpuscular volume (MCV), platelet count (PLT) and white blood cells (WBCs) were quantified in heparinized blood samples using an automatic blood analyzer (ABX Micros 60 manufactured by HORIBA ABX SAS). Markers of liver function including liver enzymes (alanine transaminase (ALT), aspartate transaminase (AST), alkaline phosphatase (ALP), gamma-glutamyl transferase (GGT) and lactate dehydrogenase (LDH)), total bilirubin, protein profile (total protein and albumin) and lipid profile (total cholesterol (TC) and triglycerides (T.Gs)) were estimated in sera samples by colorimetric methods following the instruction of the commercially available kits (Spectrum Diagnostics Egyptian Company for Biotechnology, Cairo, Egypt).

\section{Markers of oxidative stress}

These markers were assayed in supernatants of liver tissue homogenates. Activities of superoxide dismutase (SOD) and catalase (CAT) enzyme were assayed as Unit per gram of tissue according to methods suggested by Nishikimi et al., (1972) and Aebi (1984), respectively. Levels of total antioxidant capacity (TAC) (Koracevic et al., 2001) and reduced glutathione (GSH) (Beutler et al., 1963) were determined as $\mathrm{mM} / \mathrm{L}$ and $\mathrm{mg} / \mathrm{g}$ tissue, respectively. Products of the peroxidation reactions including lipid peroxidation product (LPO) (Ohkawa et al., 1979) and total protein carbonyl content (TPC) (Levine et al., 1994) were quantified as nmol/g wet tissue and nmol of reactive carbonyl compounds per mg protein of tissue, respectively. Nitrite level (an Index of Nitric 
Oxide) was measured as $\mathrm{nm} / \mathrm{g}$ tissue by colorimetric method using Griess reagent (Green et al., 1982).

\section{Liver inflammatory and fibrotic biomarkers}

Markers of inflammatory reactions including tumor necrosis factor- $\alpha$ (TNF- $\alpha$ ) and interleukin-6 (IL-6) were assessed in liver tissue homogenates as $\mathrm{Pg} / \mathrm{g}$ tissue using quantitative sandwich enzyme immunoassay technique according to the methods suggested by Engelmann et al., (1990) and March et al., (1985), respectively. The level of the hydroxyproline (fibrotic biomarker) was assayed as $\mathrm{kg} / \mathrm{mg}$ tissue according to the method described by Reddy and Enwemeka (1996).

\section{Histopathological examination}

Liver specimens were harvested from all groups, then fixed in neutral buffered formalin $(10 \%)$ and routinely processed according to the method suggested by Suvarna et al., (2019). The tissue sections were prepared with thickness $5 \mu \mathrm{m}$ and stained with Hematoxylin and Eosin (H\&E) as well as Masson's trichrome (MTC) for detection of collagen fibers for histopathological examination by a light microscope (Olympus BX50, Tokyo, Japan). The section was examined at 5 microscopic fields and scored between 0 - 3. Histopathological scores were assessed using histology activity index (HAI) score. This method is a combined score for degeneration and necrosis, inflammation and fibrosis (Elizabeth, 2000). Grade of the severity score might be 0 (no damage), 1 (mild; $<1 / 3$ of lobules), 2 (moderate; 1/3-2/3 of lobules) or 3 (severe damage; $>2 / 3$ of lobules). In addition, fibrosis staging was defined as 0 (no fibrosis), 1 (perisinusoidal and/ or pericentral), 2 (incomplete central/central bridging fibrosis), 3 (portal-portal or portal-central fibrosis) and 4 (cirrhosis). The MTC stained sections were used for obtained the average area \% of blue-stained collagen bundles within each group using imaging analysis software (Image J software).

\section{Statistical analysis}

Results were expressed in Tables and Figures as mean \pm standard error (SE). They were statistically analyzed by one-way analysis of variance test (one-way ANOVA) using the Statistical Package for Social Sciences (SPSS windows, version 11.0) followed by Bonferoni test as
Post-Hoc. The differences were considered statistically significant between the groups at a "P" value of less than 0.05 .

\section{Results}

\section{The structural properties of prepared M-NPS}

Data presented in Figure 1a showed that the sharp peak identified at $456 \mathrm{~nm}$ confirms the synthesis of Ag-NPs. As shown in Figure 1b, the sharp peak identified in the UV-visible spectrum at $375 \mathrm{~nm}$ confirms the formation of ZnO-NPs. Data illustrated in Figure 1c showed that the XRD result of the prepared Ag-NPs generates a typical crystalline metallic Ag phase and the characteristic peaks of metallic Ago were noticed at $37.8^{\circ}, 44.5^{\circ}$, and $67.6^{\circ}$ matching with the crystallographic planes (lll 111$),\left(\begin{array}{ll}0 & 0\end{array}\right.$ 2 ) and (ll $\left.\begin{array}{ll}0 & 2\end{array}\right)$ of Ag-NPs, respectively. Furthermore, the XRD showed separate diffraction peaks around $37.8^{\circ}$ and indexed by the (002) of the cubic face-centered silver. As presented in Figure 1d, the XRD pattern of ZnO-NPs showed peaks identified at $2 \theta=31.7,34.4$, $36.2,47.5,56.5,62.7,67.8$ and 68.1 and assigned to (100), (002), (101), (102), (110), (103), (112) and (201). No characteristic peaks were identified for the impurities and this indicated synthesis of ZnO-NPs with high quality. As illustrated in Figure 2a, the TEM data showed that AgNPs are round or predominantly spherical in their shapes. Some of the Ag-NPs were irregular in shape, although AgNPs were well dispersed. No aggregations were detected. As presented in Figure 2b, the TEM images confirmed that the morphological shape of ZnO-NPs that were biosynthesized with approximate size of 40-90 nm. Data of the TEM were in agreement with the UV and XRD data. TEM images of the synthesized $\mathrm{ZnO}-\mathrm{NPs}$ confirmed their hexagonal structure that implies more ionicity leading to enhancing the catalytic activity. As illustrated in Figure $2 c$, it was found that the particle size distribution of the fabricated Ag-NPs has main diameter of around $85 \mathrm{~nm}$. The hydrodynamic size of ZnO-NPs was about $155 \mathrm{~nm}$ as revealed in Figure 2d.

The in vitro biological activity of aqueous Purslane extract before and after incorporating metal nanoparticles (M-NPs)

The biological activities of aqueous Purslane extract before and after incorporating M-NPs were measured

Table 1. The Biological Activities of Egyptian Purslane Extract before and after Incorporating Silver (Ag-NPs) and Zinc Oxide Nanoparticles (ZnO-NPs).

\begin{tabular}{|c|c|c|c|c|c|c|}
\hline \multicolumn{2}{|l|}{ Extract } & P. Extract & $\begin{array}{c}\text { Ag-P. } \\
\text { nano-extract }\end{array}$ & $\begin{array}{c}\mathrm{ZnO}-\mathrm{P} . \\
\text { nano-extract }\end{array}$ & $\begin{array}{c}\text { Ascorbic acid } \\
\text { (Standard) }\end{array}$ & $\begin{array}{c}\text { Acarbose } \\
\text { (Standard) }\end{array}$ \\
\hline \multicolumn{2}{|c|}{ Total Polyphenols (mg gallic acid/100 gm) } & $62.36 \pm 0.50$ & $140.96 \pm 3.75^{\mathrm{a}}$ & $226.27 \pm 0.99 *$ ab & - & - \\
\hline \multicolumn{2}{|c|}{ Total Condensed Tannins $(\mu \mathrm{g} / \mathrm{ml})$} & $23.69 \pm 0.28$ & $32.69 \pm 0.29^{\mathrm{a}}$ & $45.96 \pm 0.12 * a b$ & - & - \\
\hline \multicolumn{2}{|c|}{ TAC (mg gallic acid/gm) } & $183.90 \pm 2.13$ & $298.86 \pm 2.47^{\mathrm{a}}$ & $478.41 \pm 1.31^{* a b}$ & - & - \\
\hline \multicolumn{2}{|c|}{ Iron Reducing Power $(\mu \mathrm{g} / \mathrm{mL})$} & $74.08 \pm 2.42$ & $136.42 \pm 2.32^{\mathrm{a}}$ & $164.26 \pm 2.81^{* a b}$ & - & - \\
\hline \multirow{2}{*}{$\begin{array}{l}\text { Scavenging } \\
\text { activity }\end{array}$} & Inhibition of DPPH $\left(\mathrm{IC}_{50} \mu \mathrm{g} / \mathrm{ml}\right)$ & $11.23 \pm 0.01$ & $8.97 \pm 0.07^{\mathrm{a}}$ & $4.69 \pm 0.01^{* a b}$ & $4.28 \pm 0.04$ & - \\
\hline & Inhibition of ABTS (\%) & $26.94 \pm 0.09$ & $38.92 \pm 0.12^{\mathrm{a}}$ & $45.88 \pm 0.12^{* a b}$ & $38.84 \pm 0.14$ & - \\
\hline \multirow[t]{2}{*}{ Inhibition (\%) } & $\alpha$-Amylase & $35.08 \pm 0.05$ & $63.03 \pm 0.08^{\mathrm{a}}$ & $63.04 \pm 0.06^{\mathrm{a}}$ & - & $67.92 \pm 0.09$ \\
\hline & $\mathrm{AChE}$ & $12.84 \pm 0.04$ & $32.07 \pm 0.08^{\mathrm{a}}$ & $55.87 \pm 0.11^{* a b}$ & - & - \\
\hline
\end{tabular}

*, The most effective extract; Values were calculated from three replicates and expressed as mean \pm SE. a, indicates the significant difference at $\mathrm{P}<0.05$ in comparison to the native extract; $\mathrm{b}$, indicates the significant difference at $\mathrm{P}<0.05$ in comparison to Ag-P. nano-extract. 

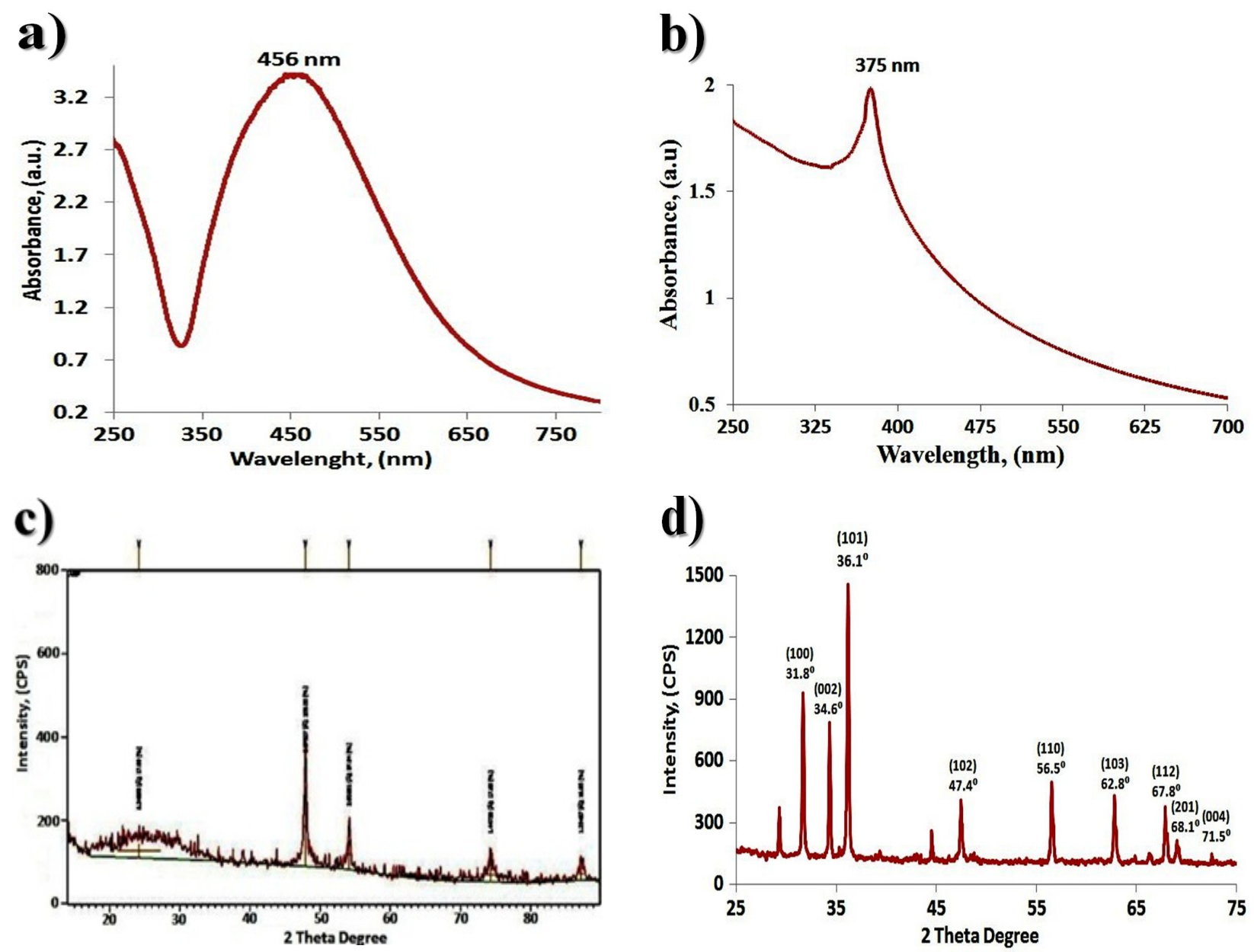

Figure 1. Characterization of the Synthesized Metal Nanoparticles (M-NPs) Showing a) Ultraviolet-visible (UV-VIS) spectrum of Ag-NPs, b) UV-VIS spectrum of ZnO-NPs, c) X-Ray Diffraction (XRD) spectrum of Ag-NPs, d) XRD spectrum of $\mathrm{ZnO}-\mathrm{NPs}$.

by quantifying the major phyto-constituents (total polyphenols and total condensed tannins) in addition to assaying the TAC, iron reducing power, free radicals scavenging activity, and the inhibitory effect on $\alpha$-amylase and AChE activity. Data depicted in Table 1 showed that concentrations of the total polyphenols and total condensed tannins increased significantly $(\mathrm{P}<0.05)$ after incorporating $\mathrm{ZnO}-\mathrm{NPs}$ as compared to the Ag-P. nano-extract and the native extract itself. Consequently, the $\mathrm{ZnO}-\mathrm{P}$. nano-extract exhibited the highest antioxidant

Table 2. Cytotoxic Activity of Egyptian Purslane Extract before and after Incorporating Silver (Ag-NPs) and Zinc Oxide Nanoparticles (ZnO-NPs) against Human Colon Cancer (CACO-2).

\begin{tabular}{|c|c|c|c|c|c|c|}
\hline \multicolumn{7}{|c|}{ Before incorporating M-NPs } \\
\hline Conc. $(\mu \mathrm{g} / \mathrm{ml})$ & 0 & 62.5 & 125 & 250 & 500 & 1000 \\
\hline Mean OD & 0.74 & 0.72 & 0.7 & 0.65 & 0.58 & 0.51 \\
\hline Viability \% & 100 & 97.44 & 94.48 & 88.06 & 78.54 & 68.57 \\
\hline $\mathrm{IC}_{50} \%$ & \multicolumn{6}{|c|}{2227} \\
\hline \multicolumn{7}{|c|}{ After incorporating Ag-NPs } \\
\hline Conc. $(\mu \mathrm{g} / \mathrm{ml})$ & 0 & 62.5 & 125 & 250 & 500 & 1000 \\
\hline Mean OD & 0.67 & 0.6 & 0.52 & 0.41 & 0.21 & 0.1 \\
\hline Viability \% & 100 & 89.39 & 76.8 & 61.68 & 31.78 & 14.82 \\
\hline $\mathrm{IC}_{50} \%$ & \multicolumn{6}{|c|}{310.7} \\
\hline \multicolumn{7}{|c|}{ After incorporating $\mathrm{ZnO}$-NPs } \\
\hline Conc. $(\mu \mathrm{g} / \mathrm{ml})$ & 0 & 62.5 & 125 & 250 & 500 & 1000 \\
\hline Mean OD & 0.74 & 0.71 & 0.67 & 0.64 & 0.55 & 0.1 \\
\hline Viability \% & 100 & 96.18 & 89.67 & 86.17 & 73.64 & 13.56 \\
\hline $\mathrm{IC}_{50} \%$ & \multicolumn{6}{|c|}{633.7} \\
\hline
\end{tabular}



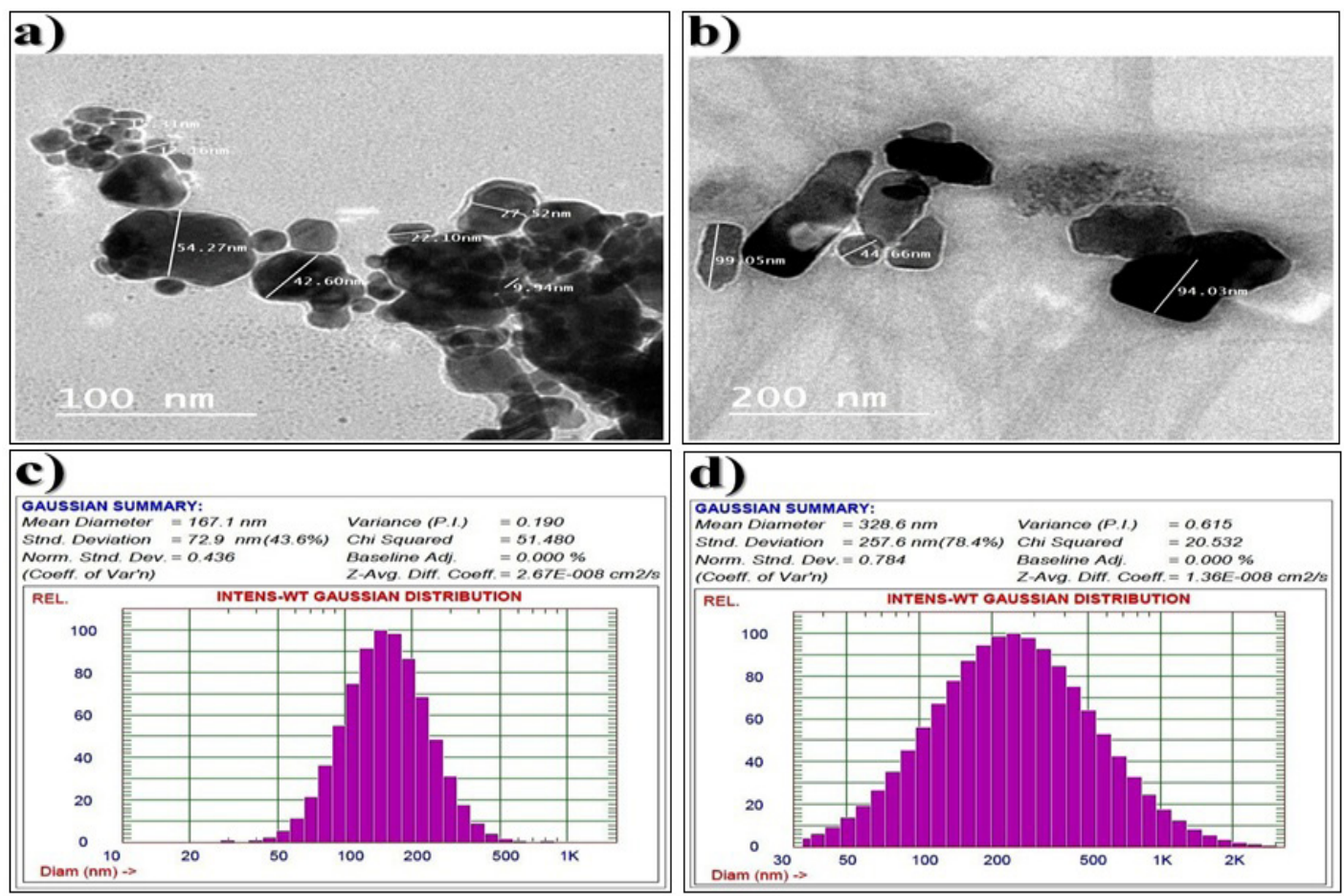

Figure 2. Characterization of the Synthesized Metal Nanoparticles (M-NPs) Incorporated into Egyptian Purslane Extract Showing. a, Transmission Electron Microscope (TEM) image of Ag-NPs; b, TEM image of ZnO-NPs; c, Dynamic Light Scattering (DLS) of Ag-NPs; d, DLS of ZnO-NPs.

activity through the significant $(\mathrm{P}<0.05)$ elevation in TAC, iron reducing power and free radicals (DPPH and ABTS) scavenging activity as compared to the other nano-extract.

As regard to the inhibitory effect on $\alpha$-amylase and AChE activities, it was noticed that P. extract at equal concentrations exhibited the same inhibitory effect after incorporation Ag-NPs and $\mathrm{ZnO}-\mathrm{NPs}$ using acarbose as standard. Both of the Ag- and ZnO-P. nano-extracts exhibited a significant $(\mathrm{P}<0.05)$ higher inhibitory effect than that in the native $\mathrm{P}$. extract. $\mathrm{ZnO}-\mathrm{P}$. nano-extract showed a significant $(\mathrm{P}<0.05)$ inhibitory effect on $\mathrm{AChE}$ activity higher than that in Ag-P. nano-extract and the extract itself.
As recorded in Table 2 and illustrated in Figure 3 that showed the maximum (Conc. $1,000 \mu \mathrm{g} / \mathrm{ml}$ ) and $\mathrm{IC}_{50}$ of native $\mathrm{P}$. extract and its $\mathrm{Ag}$ - and $\mathrm{ZnO}-\mathrm{P}$. nano-extracts compared to control CACO-2 cells, it was noticed that the Ag-P. nano-extract exhibited the highest cytotoxic activity ( $\mathrm{IC}_{50} 310.70 \mu \mathrm{g} / \mathrm{mL}$ ) against CACO-2 cells compared to the native extract and its $\mathrm{ZnO}$-nano-extract $\left(\mathrm{IC}_{50} 2227.00\right.$ and $633.70 \mu \mathrm{g} / \mathrm{mL}$, respectively). As regards to the in vitro cytotoxic activity against HEPG-2, Figure 4 showed the maximum (Conc. $1,000 \mu \mathrm{g} / \mathrm{ml}$ ) and $\mathrm{IC}_{50}$ of native P. extract and its $\mathrm{Ag}$ - and $\mathrm{ZnO}-\mathrm{P}$. nano-extracts compared to control HEPG-2 cells. It was found that the lowest IC50 value $(242.20 \mu \mathrm{g} / \mathrm{mL})$ was noticed with $\mathrm{ZnO}-\mathrm{P}$. nano-extract

Table 3. Cytotoxic Activity of Egyptian Purslane Extract before and after Incorporating Silver (Ag-NPs) and Zinc Oxide Nanoparticles (ZnO-NPs) against Human Liver Cancer (HEPG-2).

\begin{tabular}{|c|c|c|c|c|c|c|}
\hline \multicolumn{7}{|c|}{ Before incorporating M-NPs } \\
\hline Conc. $(\mu \mathrm{g} / \mathrm{ml})$ & 0 & 62.5 & 125 & 250 & 500 & 1000 \\
\hline Mean OD & 0.49 & 0.44 & 0.41 & 0.38 & 0.34 & 0.16 \\
\hline Viability \% & 100 & 90.36 & 83.37 & 77.26 & 69.93 & 32.72 \\
\hline $\mathrm{IC}_{50} \%$ & \multicolumn{6}{|c|}{702.7} \\
\hline \multicolumn{7}{|c|}{ After incorporating Ag-NPs } \\
\hline Conc. $(\mu \mathrm{g} / \mathrm{ml})$ & 0 & 62.5 & 125 & 250 & 500 & 1000 \\
\hline Mean OD & 0.34 & 0.28 & 0.21 & 0.17 & 0.15 & 0.11 \\
\hline Viability \% & 100 & 80.59 & 61.56 & 51.02 & 44.68 & 32.49 \\
\hline $\mathrm{IC}_{50} \%$ & \multicolumn{6}{|c|}{320.9} \\
\hline \multicolumn{7}{|c|}{ After incorporating $\mathrm{ZnO}-\mathrm{NPs}$} \\
\hline Conc. $(\mu \mathrm{g} / \mathrm{ml})$ & 0 & 62.5 & 125 & 250 & 500 & 1000 \\
\hline Mean OD & 0.49 & 0.46 & 0.33 & 0.21 & 0.15 & 0.1 \\
\hline Viability \% & 100 & 94.09 & 68.02 & 41.96 & 30.07 & 19.62 \\
\hline $\mathrm{IC}_{50} \%$ & \multicolumn{6}{|c|}{242.2} \\
\hline
\end{tabular}




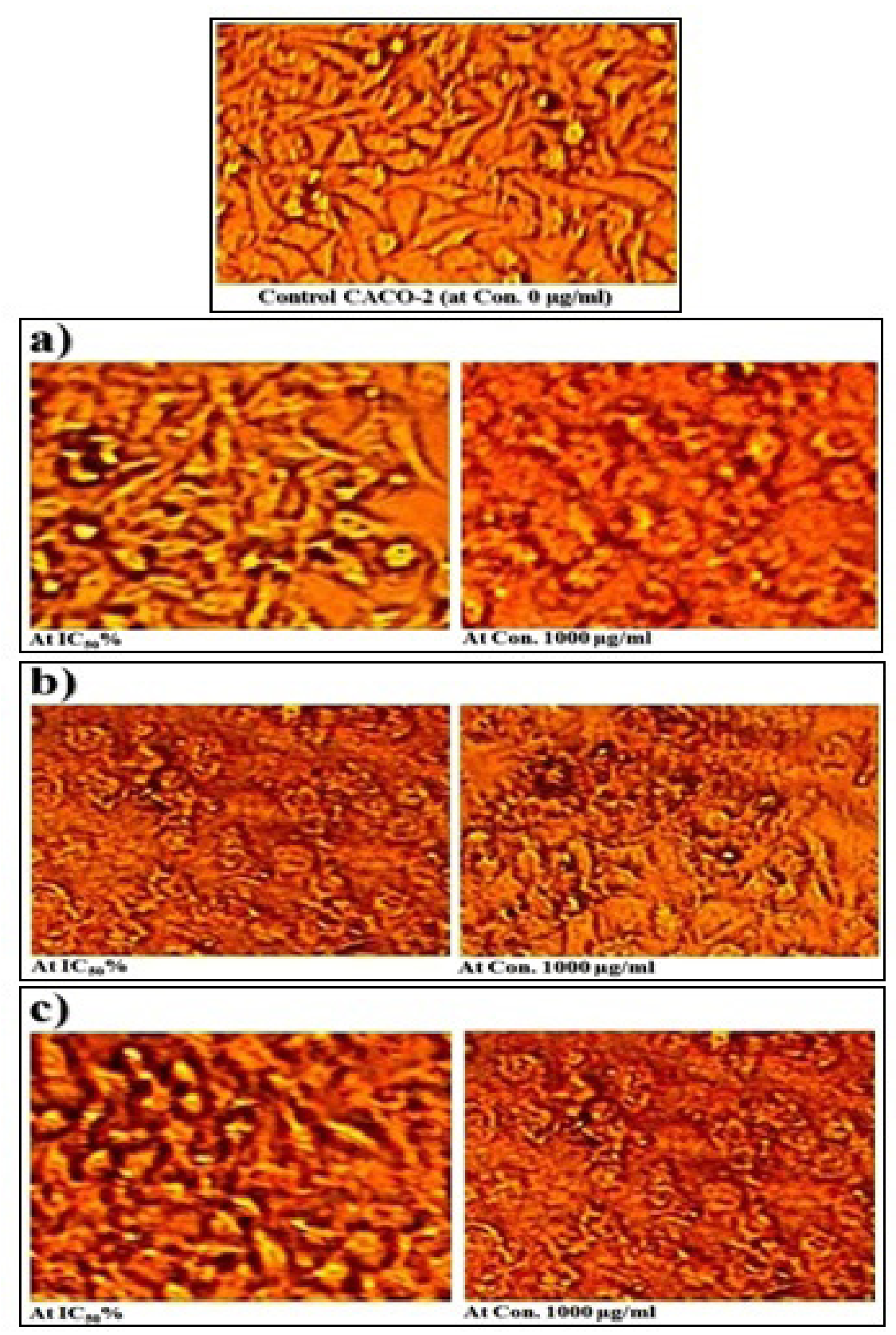

Figure 3. Cytotoxic Activity Showing the Maximum (Conc. $1000 \mu \mathrm{g} / \mathrm{ml}$ ) and Median Inhibitory Concentration (IC ${ }_{50}$ ) of a, Egyptian Purslane extract; b, Purslane extract after incorporating silver nanoparticles (Ag-NPs), and c, Purslane extract after incorporating zinc oxide nanoparticles (ZnO-NPs) against human colon cancer (CACO-2).

followed by the Ag-P. nano-extract $(320.90 \mu \mathrm{g} / \mathrm{mL})$ then the native P. extract $(702.70 \mu \mathrm{g} / \mathrm{mL})$ (Table 3). Therefore, $\mathrm{ZnO}-\mathrm{P}$. nano-extract was selected for undergoing further studies on HEPG-2 cells and compared to the native extract itself.

During the current study, it was found that treatment of HEPG-2 with ZnO-P. nano-extract decreased the fold changes of EGFR and Bcl 2 genes and increased it in Casp3 (Figure 5a). Data depicted in Table 4 showed that $\mathrm{ZnO}-\mathrm{P}$. nano-extract caused significant changes in expression of the EGFR, Bcl2, and Casp3 genes in the treated HEPG-2 cells as compared to control HEPG-2 or those cells treated with the native extract.

As illustrated in Figure 5c, the treatment with $\mathrm{ZnO}-\mathrm{P}$. nano-extract increased percentage of the total apoptotic cells $(33.82 \%)$, decreased percentage of the early apoptotic cells $(2.51 \%)$, and increased the late apoptotic cells $(21.88 \%)$ as compared to control HEPG-2 or those cells treated with the native extract itself. Data of the flow cytometric analysis presented in Figure 6 and using Annexin V-FITC as shown in Figure 7 showed that treatment of HEPG-2 with $\mathrm{ZnO}-\mathrm{NPs}$ induced apoptosis as compared to control HEPG-2 or those cells treated with the native extract itself.

The in vivo biological activity of aqueous Purslane extract before and after incorporating metal nanoparticles $(M-N P s)$

It was found that oral administration of the P. extract incorporated with Ag- and $\mathrm{ZnO}-\mathrm{NPs}$ caused no toxicity in experimental animals. The LD50 values of the native extract and its Ag- and $\mathrm{ZnO}$-nano-extracts were about 

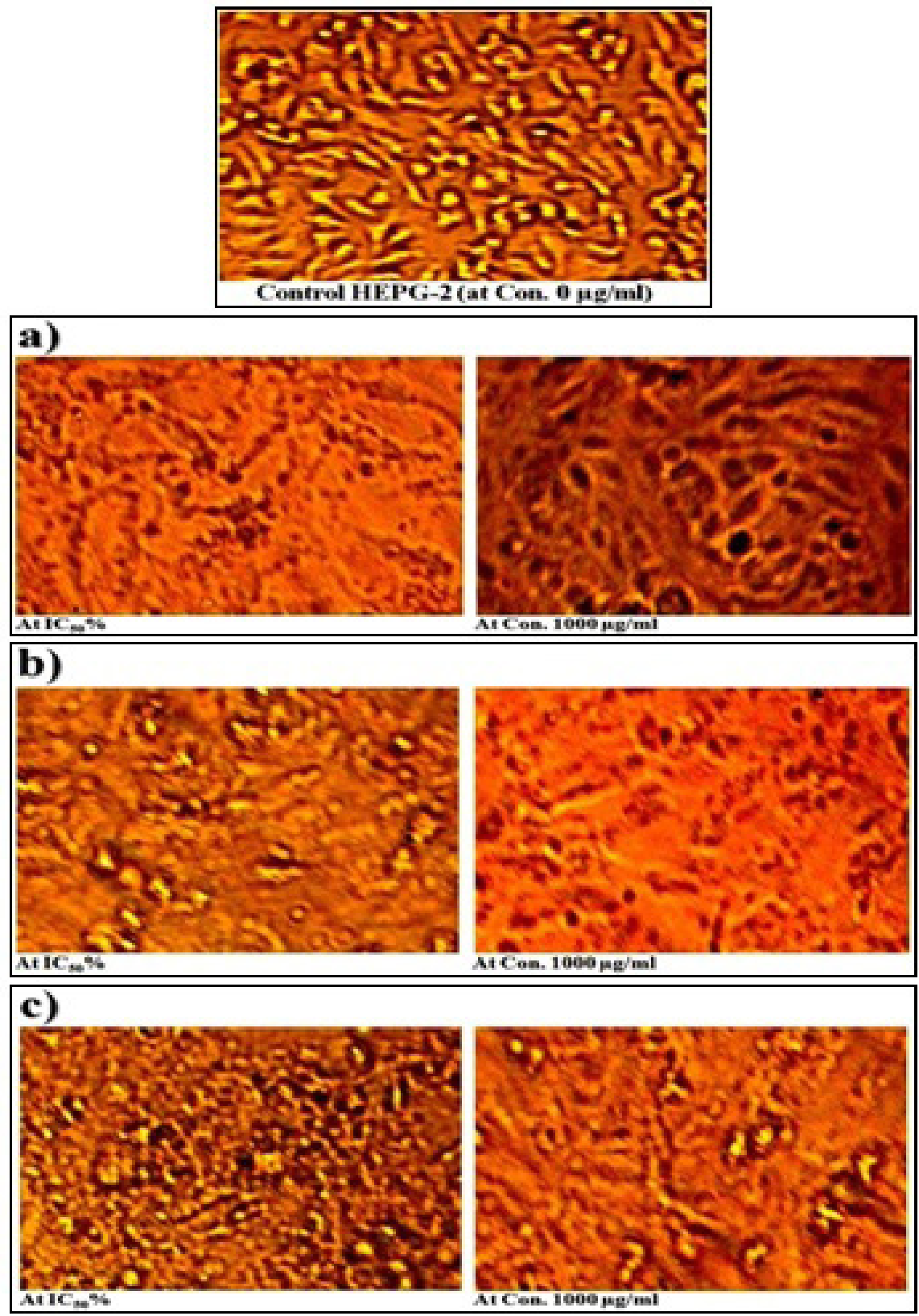

Figure 4. Cytotoxic Activity Showing the Maximum (Conc. $1000 \mu \mathrm{g} / \mathrm{ml}$ ) and Median Inhibitory Concentration $\left(\mathrm{IC}_{50}\right)$ of a, Egyptian Purslane extract; b, Purslane extract after incorporating silver nanoparticles (Ag-NPs), c, Purslane extract after incorporating zinc oxide nanoparticles (ZnO-NPs) against human liver cancer (HEPG-2).

\section{4,500, 8,000 and 9,000 $\mathrm{mg} / \mathrm{Kg}$, respectively (Figure 8).}

During the current study, efficiency P. extracts before and after incorporating Ag- and ZnO-NPs were studied against hepatic fibrosis induced by TAA in rats. As recorded in Table 5 and illustrated in Figure 9, the final total body weight declined significantly $(\mathrm{P} \leq 0.05)$ with respect to the initial body weights in the TAA treated group. Furthermore, the liver weight increased significantly $(\mathrm{P} \leq 0.05)$ in TAA treated group. Administration of $\mathrm{ZnO}-\mathrm{P}$. nano-extract restored the body and liver weights to normal values more than Ag-P. nano-extract.

Injection of TAA decreased levels of RBCs, HB, HCT and MCV significantly $(\mathrm{P} \leq 0.05)$, but it caused a significant $(\mathrm{P} \leq 0.05)$ elevation in WBCs count (Table 6). Administration of the $\mathrm{ZnO}-\mathrm{P}$. nano-extract restored levels of the hematological measurements to normal values.
Data compiled in Table 7 revealed that activities of the hepatic enzymes (ALT, AST, ALP, GGT, and LDH) and level of bilirubin elevated significantly $(\mathrm{P} \leq 0.05)$ in sera of TAA treated group. Administration of $\mathrm{ZnO}-\mathrm{P}$. nano-extract decreased activities of the hepatic specific enzymes and bilirubin level to normal levels. Levels of T. protein and albumin decreased significantly $(\mathrm{P} \leq 0.05)$ in TAA treated group. The native P. extract and its Agnano-extract opposed the deleterious effect of TAA indicating improvement of liver functions while the $\mathrm{ZnO}-\mathrm{P}$. nano-extract restored the hepatic functions to a normal physiological state. Levels of the TC and T.Gs increased significantly $(\mathrm{P} \leq 0.05)$ in sera of the TAA treated group. The $\mathrm{ZnO}-\mathrm{P}$. nano-extract decreased levels of the lipid measurements to normal values.

It was found that TAA caused a significant $(\mathrm{P} \leq 0.05)$ 
Table 4. Data of the EGFR, Bcl2 and Casp3 Genes Expression in Human Liver Cancer (HEPG-2) Treated with Egyptian Purslane Extract before and after Incorporating Zinc Oxide Nanoparticles (ZnO-NPs).

\begin{tabular}{|c|c|c|c|c|c|c|c|c|c|}
\hline \multirow[t]{4}{*}{ Extract } & & \multicolumn{8}{|c|}{ EGFR } \\
\hline & \multirow{3}{*}{ Conc. $(\mu \mathrm{M})$} & \multicolumn{3}{|c|}{ Control cells } & \multicolumn{4}{|c|}{ Test cells } & \multirow{2}{*}{$\begin{array}{c}\text { FLD } \\
2^{\wedge-\Delta \Delta C T}\end{array}$} \\
\hline & & GAPDH & EGFR & $\triangle \mathrm{CTC}$ & GAPDH & EGFR & $\Delta \mathrm{CTE}$ & $\Delta \Delta \mathrm{CT}$ & \\
\hline & & $\mathrm{HC}$ & $\mathrm{TC}$ & TC-HC & HE & TE & TE-HE & $\Delta$ CTE- $\Delta$ CTC & Eamp $=1.849$ \\
\hline P. extract & & 24.05 & 27.66 & 3.61 & 23.61 & 28.08 & 4.47 & 0.86 & 0.5894327 \\
\hline ZnO-P. nano-extract & & 24.05 & 27.66 & 3.61 & 24.19 & 29.75 & 5.56 & 1.95 & 0.301629 \\
\hline Doxorubicin & & 24.05 & 27.66 & 3.61 & 23.77 & 30.26 & 6.49 & 2.88 & 0.1703028 \\
\hline Control & & 24.05 & 27.66 & 3.61 & 24.05 & 27.66 & 3.61 & 0 & 1 \\
\hline \multirow[t]{4}{*}{ Extract } & & \multicolumn{8}{|c|}{$\mathrm{Bcl} 2$} \\
\hline & & \multicolumn{3}{|c|}{ Control cells } & \multicolumn{4}{|c|}{ Test cells } & FLD \\
\hline & Conc. $(\mu \mathrm{M})$ & GAPDH & $\mathrm{Bcl} 2$ & $\Delta \mathrm{CTC}$ & GAPDH & $\mathrm{Bcl} 2$ & $\triangle \mathrm{CTE}$ & $\Delta \Delta \mathrm{CT}$ & $2^{\wedge}-\Delta \Delta \mathrm{CT}$ \\
\hline & & $\mathrm{HC}$ & $\mathrm{TC}$ & TC-HC & $\mathrm{HE}$ & $\mathrm{TE}$ & TE-HE & $\Delta \mathrm{CTE}-\Delta \mathrm{CTC}$ & Eamp $=1.849$ \\
\hline P. extract & & 24.05 & 28.02 & 3.97 & 23.61 & 28.57 & 4.96 & 0.99 & 0.5441673 \\
\hline ZnO-P. nano-extract & & 24.05 & 28.02 & 3.97 & 24.19 & 29.84 & 5.65 & 1.68 & 0.3560787 \\
\hline Doxorubicin & & 24.05 & 28.02 & 3.97 & 23.77 & 28.57 & 4.8 & 0.83 & 0.6004023 \\
\hline Control & & 24.05 & 28.02 & 3.97 & 24.05 & 28.02 & 3.97 & 0 & 1 \\
\hline \multirow[t]{4}{*}{ Extract } & & \multicolumn{8}{|c|}{ Casp3 } \\
\hline & & \multicolumn{3}{|c|}{ Control cells } & \multicolumn{4}{|c|}{ Test cells } & FLD \\
\hline & Conc. $(\mu \mathrm{M})$ & GAPDH & Casp3 & $\Delta \mathrm{CTC}$ & GAPDH & Casp3 & $\Delta \mathrm{CTE}$ & $\Delta \Delta \mathrm{CT}$ & $2^{\wedge-\Delta \Delta C T}$ \\
\hline & & $\mathrm{HC}$ & TC & TC-HC & HE & TE & TE-HE & $\Delta$ CTE- $\Delta$ CTC & Eamp $=1.849$ \\
\hline P. extract & & 24.05 & 33.92 & 9.87 & 23.61 & 31.46 & 7.85 & -2.02 & 3.4610874 \\
\hline ZnO-P. nano-extract & & 24.05 & 33.92 & 9.87 & 24.19 & 30.72 & 6.53 & -3.34 & 7.7905709 \\
\hline Doxorubicin & & 24.05 & 33.92 & 9.87 & 23.77 & 30.18 & 6.41 & -3.46 & 8.3869048 \\
\hline Control & & 24.05 & 33.92 & 9.87 & 24.05 & 33.92 & 9.87 & 0 & 1 \\
\hline
\end{tabular}

decline in activities of the antioxidants enzymes (SOD and CAT) and levels of TAC and GSH associated with significant $(\mathrm{P} \leq 0.05)$ elevation in levels of $\mathrm{NO}$ and products of the peroxidation reactions (LPO and TPC) in liver tissue homogenate (Table 8). The present study clarified the decline in oxidative stress induced by TAA via $\mathrm{ZnO}-\mathrm{P}$. nano-extract as evidenced by elevated levels of the antioxidants (SOD, CAT, and GSH) and decreasing the peroxidation products in hepatic tissues.

Data compiled in Table 9 showed that levels of inflammatory (TNF- $\alpha$ and IL-6) and fibrosis markers (Hydroxyproline) elevated significantly $(\mathrm{P} \leq 0.05)$ in liver
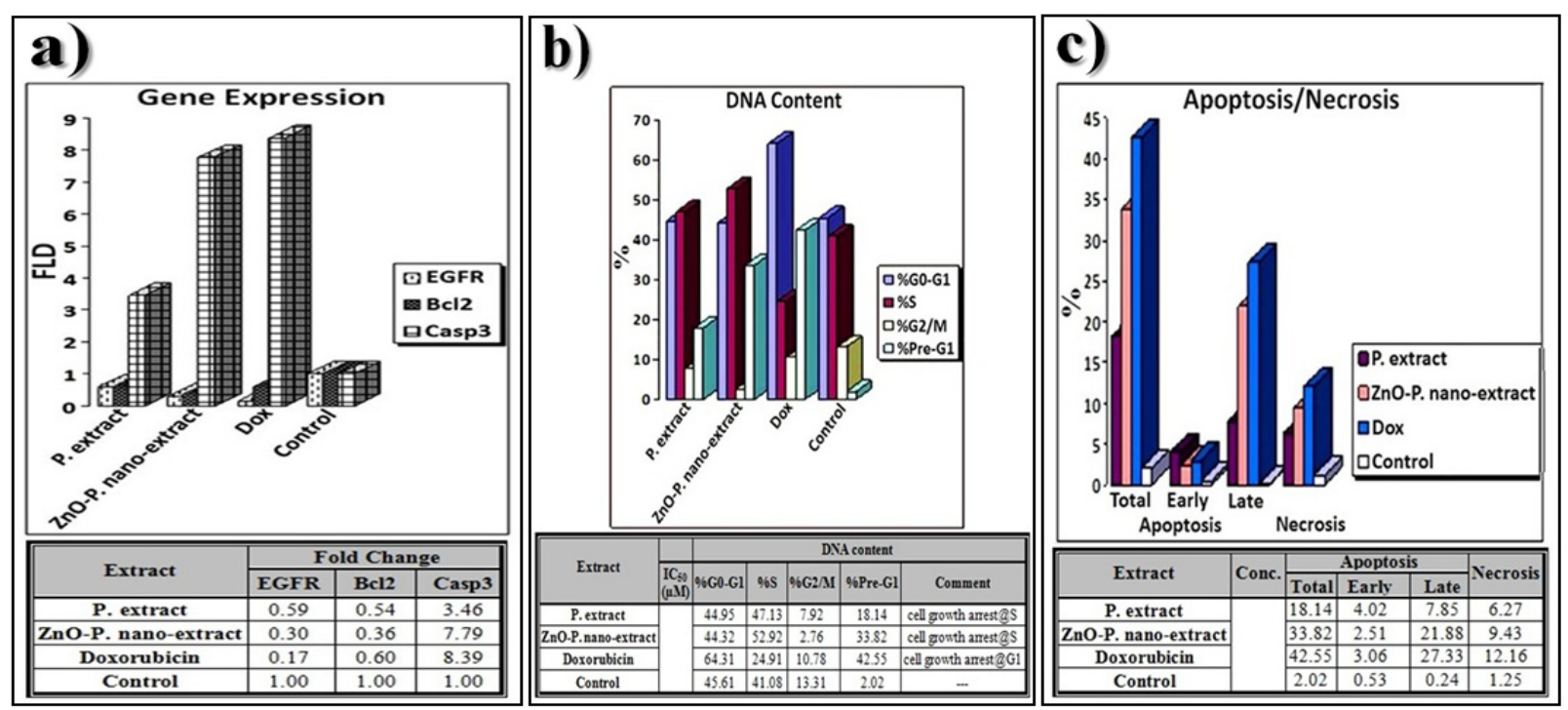

Figure 5. Chart Showing. a, The fold change in expression of the EGFR, Bcl2, and Casp3 genes; b, Cell cycle analysis; c, Apoptosis in human liver cancer (HEPG-2) treated with Egyptian Purslane extract before and after incorporating zinc oxide nanoparticles ( $\mathrm{ZnO}-\mathrm{NPs})$ and compared to control HEPG-2 before and after the treatment with Dox as standard drug. 
Table 5. Effect of Egyptian Purslane Extract before and after Incorporating Silver (Ag-NPs) and Zinc Oxide Nanoparticles (ZnO-NPs) against Thioacetamide (TAA) Induced Liver Injury on the Change in Body Weight and Liver/Body Weights Ratio in Rats

\begin{tabular}{lccccc}
\hline & Initial BW & Final BW & Liver W & Change in BW (\%) & Liver index (\%) \\
\hline C & $203.8 \pm 1.47$ & $226 \pm 1.38$ & $7.87 \pm 0.06$ & $10.91 \pm 0.47$ & $3.49 \pm 0.04$ \\
Purslane extract & $207.2 \pm 0.99$ & $228 \pm 0.98$ & $7.87 \pm 0.07$ & $10.05 \pm 0.60$ & $3.45 \pm 0.04$ \\
Ag-P. nano-extract & $207.2 \pm 0.96$ & $229 \pm 0.67$ & $7.96 \pm 0.04$ & $10.55 \pm 0.71$ & $3.47 \pm 0.02$ \\
ZnO-P. nano-extract & $208.8 \pm 0.91$ & $229.4 \pm 0.73$ & $7.89 \pm 0.05$ & $9.88 \pm 0.45$ & $3.44 \pm 0.03$ \\
TAA & $209.8 \pm 0.47$ & $187.8 \pm 0.76^{\mathrm{a}}$ & $17.52 \pm 0.08^{\mathrm{a}}$ & $-10.48 \pm 0.52^{\mathrm{a}}$ & $9.33 \pm 0.05^{\mathrm{a}}$ \\
TAA + P. extract & $207.6 \pm 0.62$ & $197.4 \pm 0.57^{\mathrm{ab}}$ & $8.58 \pm 0.03^{\mathrm{a}}$ & $-4.91 \pm 0.16^{\mathrm{ab}}$ & $4.35 \pm 0.01^{\mathrm{a}}$ \\
TAA+ Ag-P. nano-extract & $207.2 \pm 1.17$ & $227.4 \pm 1.56^{\mathrm{b}}$ & $7.82 \pm 0.05^{\mathrm{b}}$ & $9.74 \pm 0.27^{\mathrm{b}}$ & $3.44 \pm 0.05^{\mathrm{b}}$ \\
TAA+ ZnO-P. nano-extract & $207.6 \pm 0.76$ & $228.6 \pm 0.36^{\mathrm{b}}$ & $7.81 \pm 0.05^{\mathrm{b}}$ & $8.65 \pm 0.30^{\mathrm{b}}$ & $3.41 \pm 0.02^{\mathrm{b}}$ \\
\hline
\end{tabular}

Data were calculated from five replicates and expressed as mean $\pm \mathrm{SE},{ }^{\text {a }}$, significant versus control group; ${ }^{\mathrm{b}}$, significant versus TAA (toxic) group at $\mathrm{P} \leq 0.05$.

tissues of the TAA treated group. Although the native P. extract and its Ag-nano-extract decreased levels of hepatic inflammatory and fibrosis markers, it could not restore their levels to normalcy. Administration of $\mathrm{ZnO}-\mathrm{P}$. nano-extract restored levels of these hepatic markers to normal values.

\section{Histopathological investigation}

Light microscopic examination in the liver of normal control rats as well as rats treated with either P. extract, Ag-P. nano-extract or $\mathrm{ZnO}-\mathrm{P}$. nano-extract revealed the normal architecture of hepatic parenchyma (Figure 10a, b, c, and d). By contrast, liver of rats treated with TAA showed numerous histopathological alterations described as marked portal fibrosis (expansion of the portal area with fibrous tissue) (Figure 10e \& f) with bridging fibroblasts to encircle the hepatocytes which suffered from hydropic degeneration (Figure 10f). Hyperplasia of epithelial lining bile duct associated with the appearance of newly formed bile ductules (Figure 10e) and focal hepatocellular necrosis was also seen in examined sections. Meanwhile, the liver of rats treated with TAA + P. extract revealed moderate improvement in the histopathological lesions. The examined sections exhibited vacuolar degeneration of some hepatocytes and moderate fibrosis in the portal triad (Figure 10g). Furthermore, amelioration of the hepatic damage was recorded in the liver of rats treated with TAA + Ag-P. nano-extract, as it showed slight hepatocellular vacuolar degeneration and scanty fibroblasts proliferation in the portal triad (Figure 10h). In hepatic tissues of
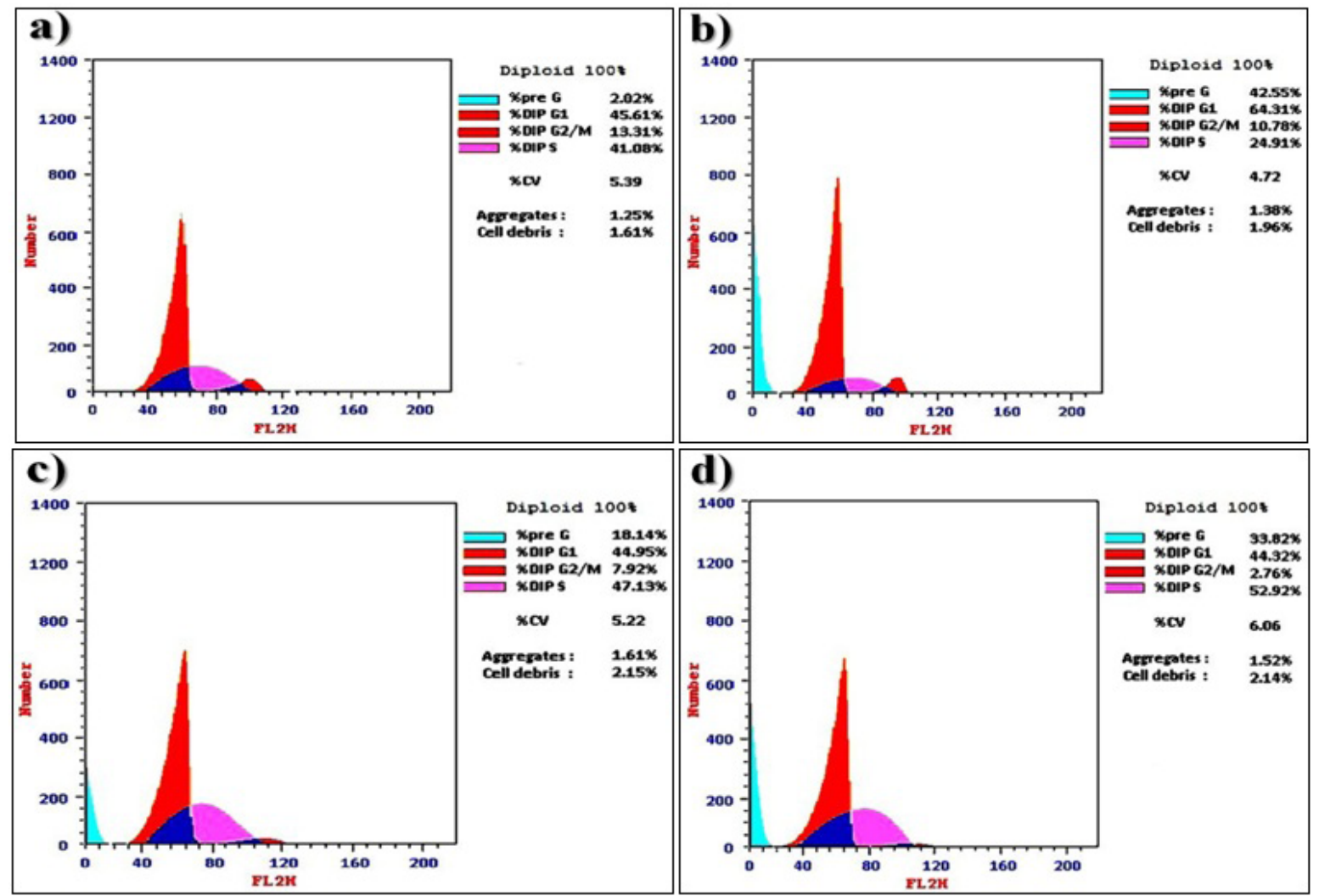

Figure 6. Data of DNA Content in a, Control HEPG-2; b, HEPG-2 treated with doxorubicin; c, HEPG-2 treated with P. extract; d, HEPG-2 treated with ZnO-P. nano-extract. 
Table 6. Effect of Egyptian Purslane Extract before and after Incorporating Silver (Ag-NPs) and Zinc Oxide Nanoparticles (ZnO-NPs) against Thioacetamide (TAA) Induced Liver Injury on Hematological Measurements in Rats

\begin{tabular}{lcccccc}
\hline & RBCs $\left(10^{6} / \mathrm{ul}\right)$ & HB $(\mathrm{g} / \mathrm{dl})$ & HCT $(\%)$ & MCV $\left(\mathrm{um}^{3}\right)$ & Platelets $\left(10^{3} / \mathrm{ul}\right)$ & WBCs $\left(10^{3} / \mathrm{ul}\right)$ \\
\hline C & $7.75 \pm 0.02$ & $12.00 \pm 0.05$ & $35.99 \pm 0.14$ & $49.93 \pm 0.05$ & $488.25 \pm 0.99$ & $8.98 \pm 0.05$ \\
Purslane extract & $7.72 \pm 0.01$ & $12.01 \pm 0.03$ & $36.03 \pm 0.10$ & $50.02 \pm 0.05$ & $489.83 \pm 0.44$ & $9.02 \pm 0.04$ \\
Ag-P. nano-extract & $7.72 \pm 0.01$ & $11.99 \pm 0.03$ & $35.98 \pm 0.09$ & $50.11 \pm 0.09$ & $489.65 \pm 0.38$ & $8.95 \pm 0.04$ \\
ZnO-P. nano-extract & $7.71 \pm 0.02$ & $12.06 \pm 0.07$ & $36.17 \pm 0.20$ & $50.15 \pm 0.07$ & $489.98 \pm 0.46$ & $8.87 \pm 0.04$ \\
TAA & $4.78 \pm 0.01^{\mathrm{a}}$ & $8.19 \pm 0.02^{\mathrm{a}}$ & $24.56 \pm 0.05^{\mathrm{a}}$ & $49.85 \pm 0.10$ & $336.56 \pm 0.55^{\mathrm{a}}$ & $23.67 \pm 0.02^{\mathrm{a}}$ \\
TAA + P. extract & $5.79 \pm 0.02^{\mathrm{ab}}$ & $10.27 \pm 0.01^{\mathrm{ab}}$ & $30.80 \pm 0.04^{\mathrm{ab}}$ & $49.84 \pm 0.07$ & $408.12 \pm 0.59^{\mathrm{ab}}$ & $14.71 \pm 0.02^{\mathrm{ab}}$ \\
TAA+ Ag-P. nano-extract & $7.71 \pm 0.01^{\mathrm{b}}$ & $12.03 \pm 0.04^{\mathrm{b}}$ & $36.10 \pm 0.11^{\mathrm{b}}$ & $49.92 \pm 0.06$ & $490.97 \pm 1.15^{\mathrm{b}}$ & $8.88 \pm 0.02^{\mathrm{b}}$ \\
TAA+ ZnO-P. nano-extract & $7.73 \pm 0.02^{\mathrm{b}}$ & $11.96 \pm 0.03^{\mathrm{b}}$ & $35.88 \pm 0.09^{\mathrm{b}}$ & $49.90 \pm 0.06$ & $449.65 \pm 0.14^{\mathrm{ab}}$ & $8.88 \pm 0.05^{\mathrm{b}}$ \\
\hline
\end{tabular}

Data were calculated from five replicates and expressed as mean $\pm \mathrm{SE},{ }^{\text {a }}$, significant versus control group; ${ }^{\mathrm{b}}$. significant versus TAA (toxic) group at $\mathrm{P} \leq 0.05$.

rats treated with TAA $+\mathrm{ZnO}-\mathrm{P}$. nano-extract, there is marked regression in the alterations demonstrated histopathologically with sparsely hepatocellular vacuolar degeneration (Figure 10i) was the only finding observed in this group.

Histochemical investigation (MTC stain for collagen)

The histochemical examination in liver tissue of normal control rats as well as rats treated with P. extract or Ag-P. nano-extract or ZnO-P. nano-extract exhibited normal histochemical reaction (Figure 11a, b, c, and d). Meanwhile liver of rats treated with TAA showed a strong positive blue MTC reaction in the portal triad (Figure 11e), indicating collagen fibers deposition. On the other hand, the treatment with TAA + P. extract revealed a moderate reaction (Figure 11f). Moreover, a weak MTC positive reaction was recorded in the liver of rats treated with TAA + Ag-P. nano-extract (Figure 11g). Furthermore, a normal histochemical reaction was noticed in the liver of rats treated with TAA $+\mathrm{ZnO}-\mathrm{P}$. nano-extract (Figure 11h). Figure 11i revealed the MTC staining area (\%) of collagen deposition in hepatic tissue of rats from different experimental groups.

\section{Discussion}

The structural properties of prepared M-NPS

$\mathrm{UV}$-Vis spectroscopy is considered a discerning and simple tool for the characterization of M-NPs. The Ag-NPs are characterized by their exceptional optical properties that strongly related to the exact light wavelengths. The
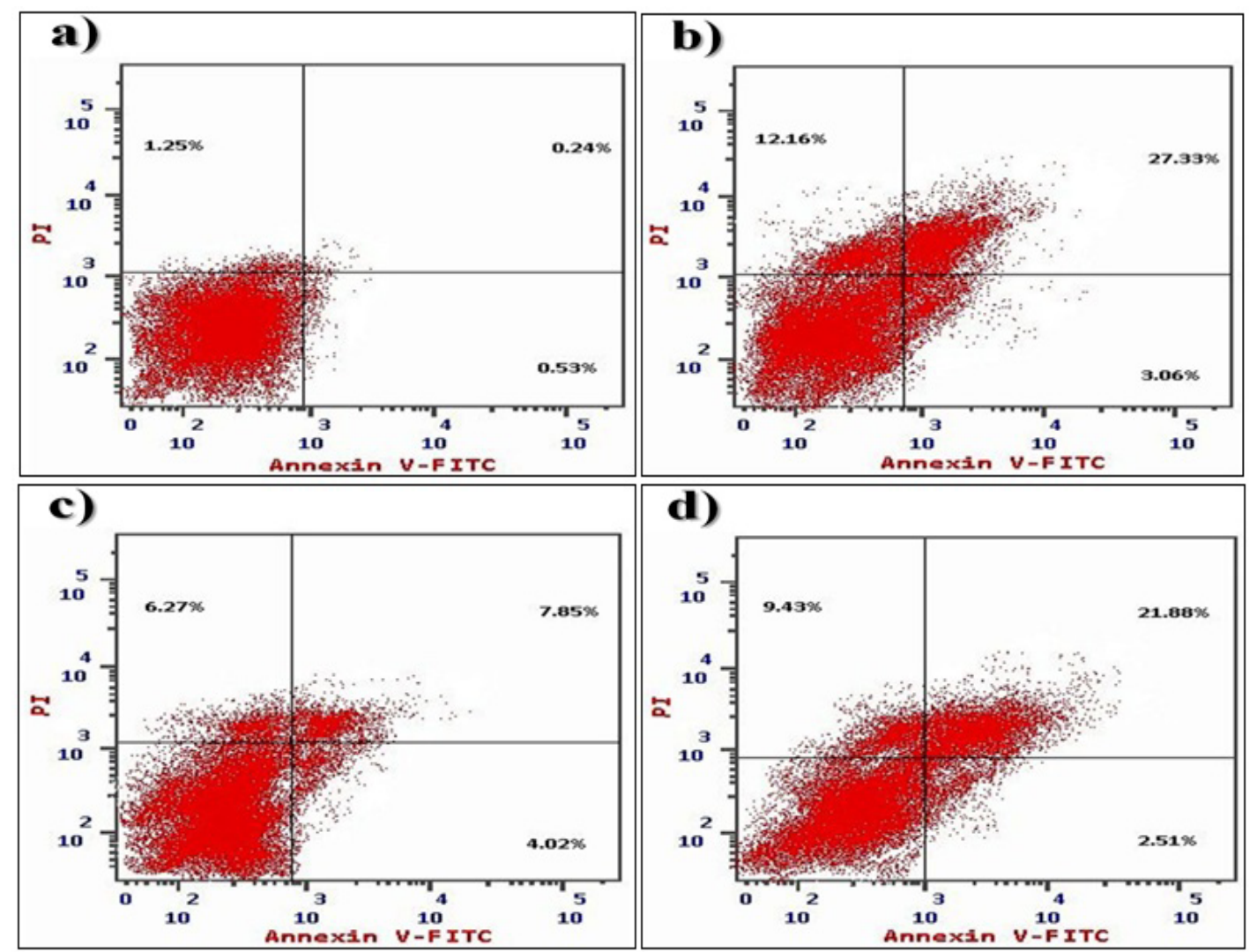

Figure 7. Data of Apoptosis Assay with Annexin V-FITC showing a, Control HEPG-2; b, HEPG-2 treated with doxorubicin; c, HEPG-2 treated with P. extract; d, HEPG-2 treated with ZnO-P. nano-extract 
DOI:10.31557/APJCP.2022.23.1.287

Metal Purslane Nano-Extract against Liver Fibrosis Induced by Thioacetamide in Rats
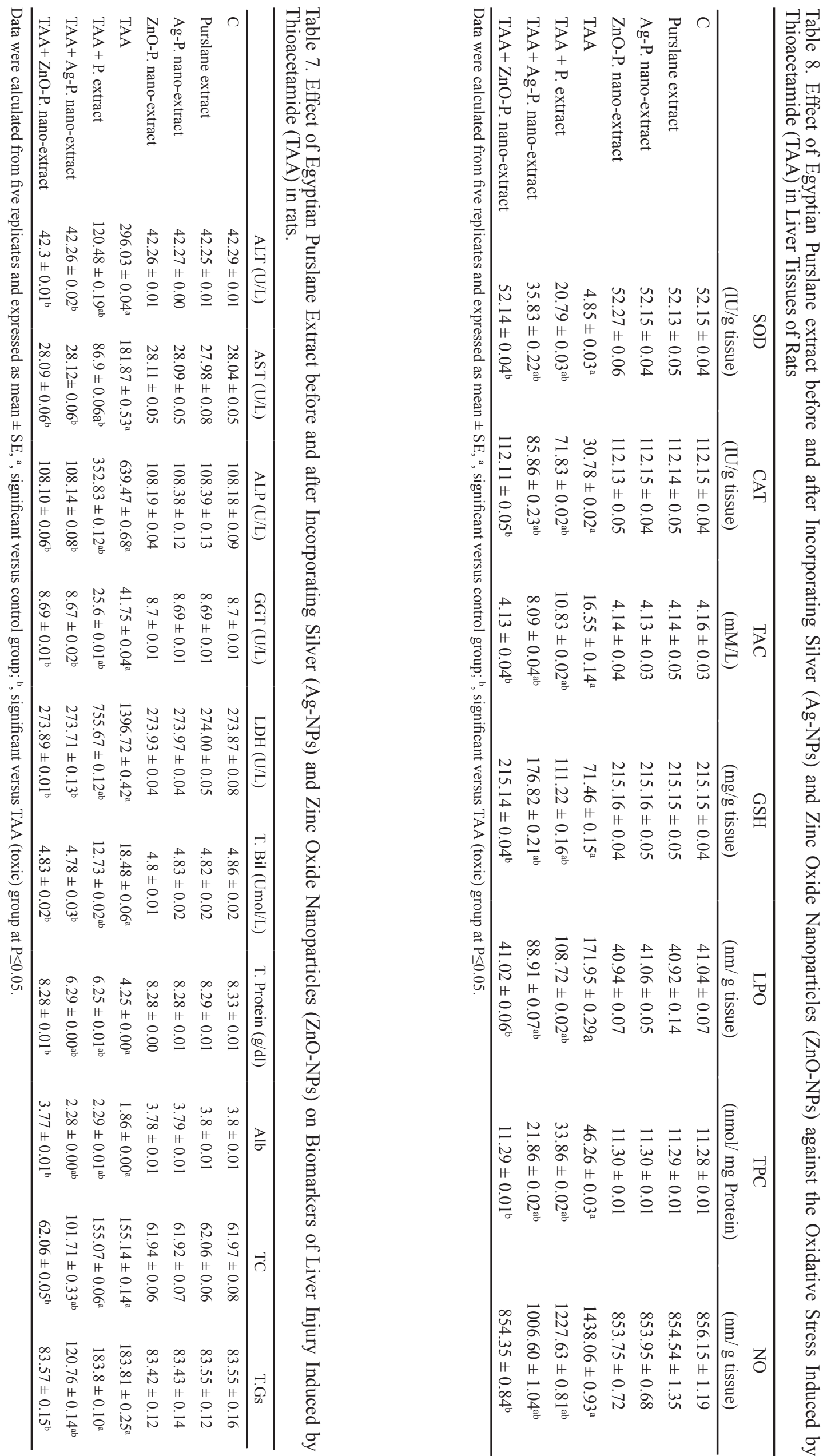


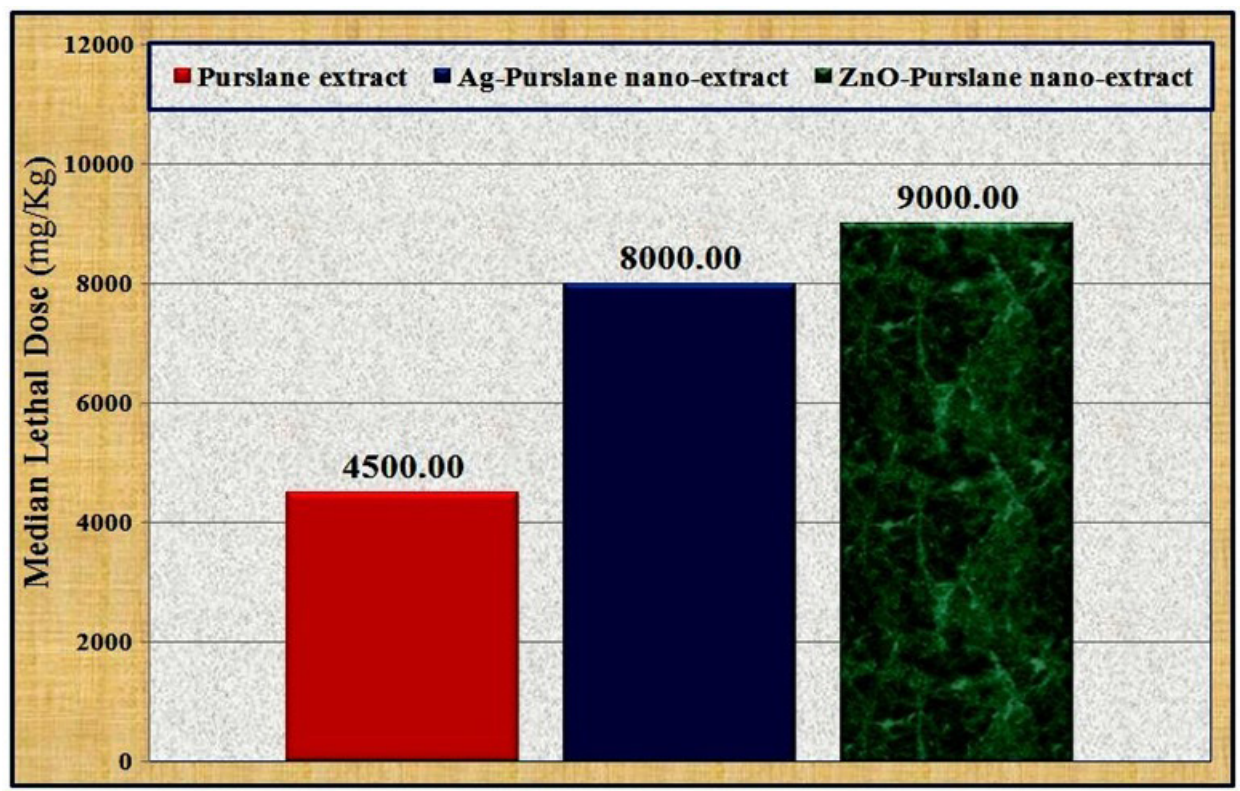

Figure 8. The Median Lethal Doses (LD50) of Egyptian Purslane Extract before and after Incorporating Silver (Ag-NPs) and Zinc Oxide Nanoparticles (ZnO-NPs).

Table 9. Effect of Egyptian Purslane Extract before and after Incorporating Silver (Ag-NPs) and Zinc Oxide Nanoparticles (ZnO-NPs) against Thioacetamide (TAA) Induced Liver Injury on Liver Inflammatory (Tumor Necrosis Factor $\alpha($ TNF- $\alpha)$ and Interleukin-6 (IL-6)) and Fibrosis Markers (Hydroxyproline) in Liver Tissues of Rats.

\begin{tabular}{lccc}
\hline & TNF- $\alpha$ (Pg/g tissue) & IL-6 (Pg/g tissue) & Hydroxyproline $(\mathrm{kg} / \mathrm{mg}$ tissue $)$ \\
\hline C & $358.90 \pm 0.73$ & $490.14 \pm 0.17$ & $0.27 \pm 0.00$ \\
Purslane extract & $358.84 \pm 0.52$ & $489.30 \pm 0.45$ & $0.27 \pm 0.00$ \\
Ag-P. nano-extract & $359.08 \pm 0.55$ & $489.70 \pm 0.29$ & $0.27 \pm 0.00$ \\
ZnO-P. nano-extract & $359.63 \pm 0.31$ & $489.50 \pm 0.17$ & $0.27 \pm 0.00$ \\
TAA & $830.72 \pm 0.29^{\mathrm{a}}$ & $1355.07 \pm 0.82^{\mathrm{a}}$ & $0.80 \pm 0.00^{\mathrm{a}}$ \\
TAA + P. extract & $648.72 \pm 0.24^{\mathrm{ab}}$ & $816.46 \pm 0.66^{\mathrm{ab}}$ & $0.59 \pm 0.00^{\mathrm{ab}}$ \\
TAA+ Ag-P. nano-extract & $648.91 \pm 0.28^{\mathrm{ab}}$ & $816.86 \pm 0.66^{\mathrm{ab}}$ & $0.58 \pm 0.00^{\mathrm{ab}}$ \\
TAA+ ZnO-P. nano-extract & $358.51 \pm 0.59^{\mathrm{b}}$ & $489.09 \pm 0.27^{\mathrm{b}}$ & $0.27 \pm 0.00^{\mathrm{b}}$ \\
\hline
\end{tabular}

Data were calculated from five replicates and expressed as mean $\pm \mathrm{SE}$, ${ }^{\text {, }}$, significant versus control group; ${ }^{\mathrm{b}}$. significant versus TAA (toxic) group at $\mathrm{P} \leq 0.05$.

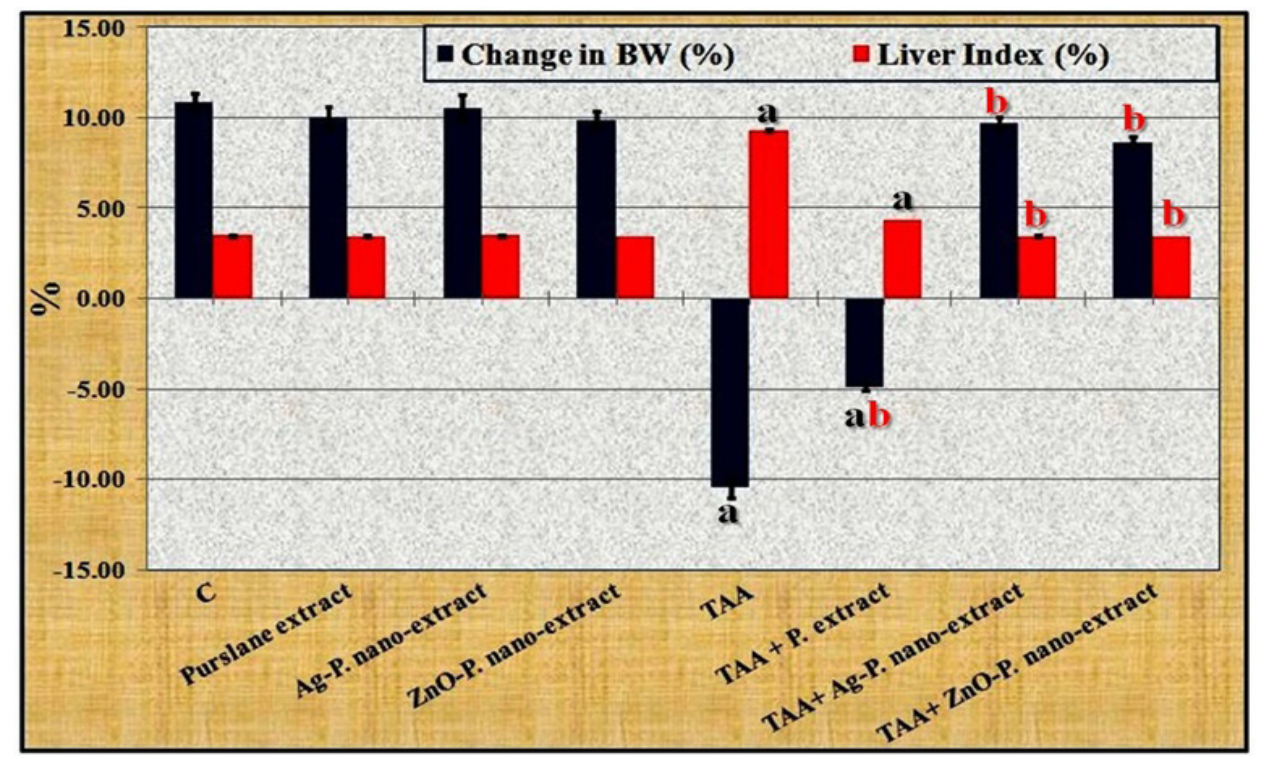

Figure 9. Effect of Egyptian Purslane Extract before and after Incorporating Silver (Ag-NPs) and Zinc Oxide Nanoparticles (ZnO-NPs) against Thioacetamide (TAA) Induced Liver Injury on Body and Liver/Body Weights Ratio in Rats. Data were calculated from five replicates and expressed as mean $\pm \mathrm{SE}$, a: significant versus control group, b: significant versus TAA (toxic) group at $\mathrm{P} \leq 0.05$ 
Metal Purslane Nano-Extract against Liver Fibrosis Induced by Thioacetamide in Rats

Table 10. The Histopathological Lesion Scores Showed the Effect of Egyptian Purslane Extract before and after IncorPorating Silver (Ag-NPs) and Zinc Oxide Nanoparticles (ZnO-NPs) against Thioacetamide (TAA) Induced Liver Injury in Liver Tissues of Rats.

\begin{tabular}{lcccc}
\hline & $\begin{array}{c}\text { Hepatocellular vacuolar / } \\
\text { hydropic degeneration }\end{array}$ & $\begin{array}{c}\text { hepatocellular } \\
\text { necrosis }\end{array}$ & $\begin{array}{c}\text { hyperplasia of biliary epithelium } \\
\text { and newly formed bile ductuoles }\end{array}$ & $\begin{array}{c}\text { Fibrosis } \\
\text { C }\end{array}$ \\
Purslane extract & 0 & 0 & 0 & 0 \\
Ag-P. nano-extract & 0 & 0 & 0 & 0 \\
ZnO-P. nano-extract & 0 & 0 & 0 & 0 \\
TAA & 3 & 0 & 0 & 0 \\
TAA + P. extract & 2 & 2 & 3 & 3 \\
TAA+ Ag-P. nano-extract & 1 & 1 & 1 & 2 \\
TAA+ ZnO-P. nano-extract & 1 & 0 & 0 & 1 \\
\hline
\end{tabular}

sharp peak that was identified at $456 \mathrm{~nm}$ confirmed Ag-NPs synthesis and this was in agreement with the study suggested by Raja et al. (2017). The peak that was identified at $375 \mathrm{~nm}$ confirmed $\mathrm{ZnO}-\mathrm{NPs}$ synthesis and this indicated the monodispersed nature of the NPs distribution (Nouroozi and Farzaneh, 2011; Talam et al.,
2012). The XRD is one of the most suitable techniques used for revealing the structural properties of nano-scaled materials. During the current study, The Ag-NPs and $\mathrm{ZnO}-$ NPs were prepared and studied using the XRD diffraction pattern. The diffraction peaks that were identified by XRD confirmed the presence of silver at the nano-scale and this

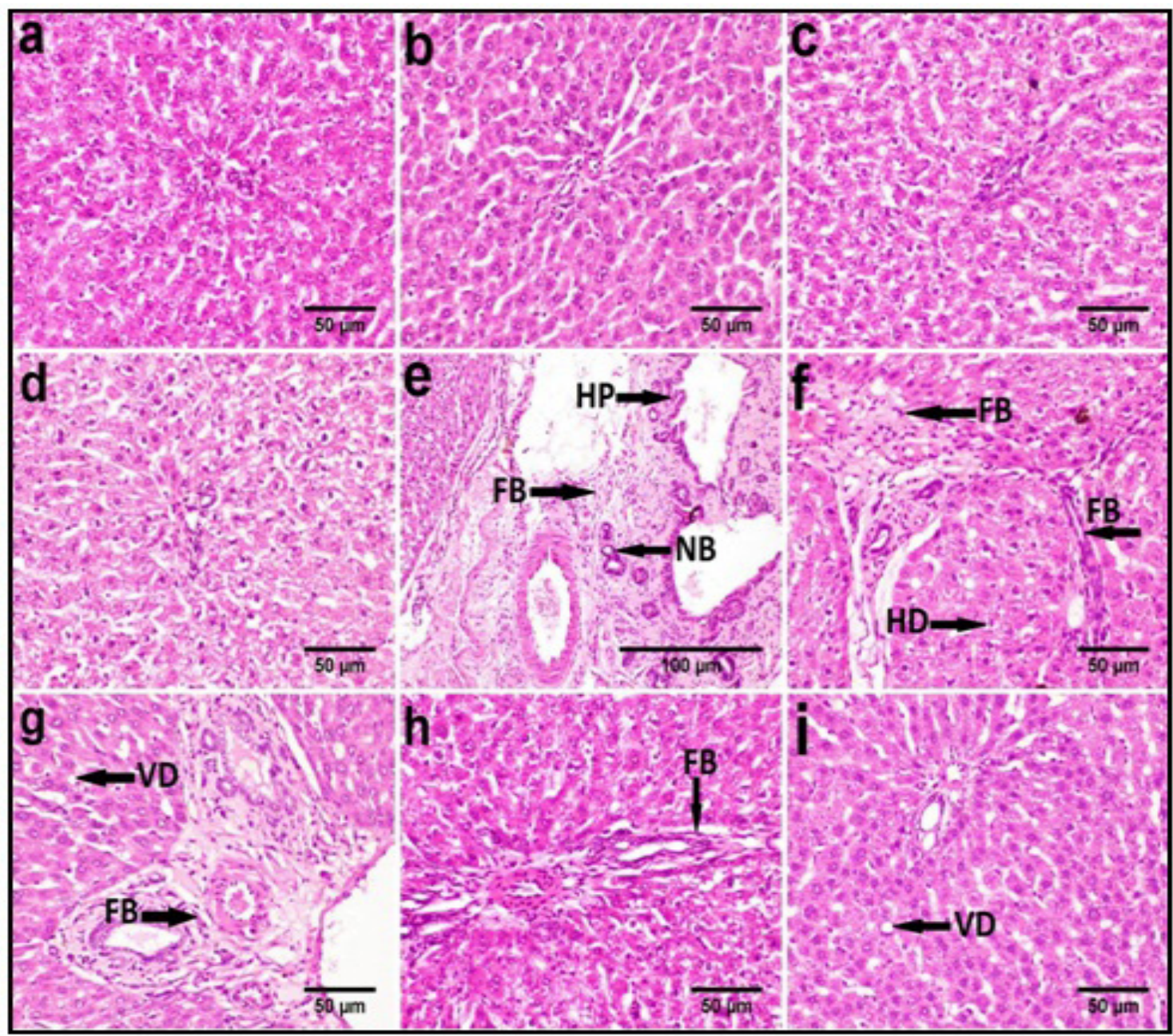

Figure 10. Representative Photomicrographs of H \& E Stained Liver Sections (scale bar 50 $\mathrm{m}$ ) of Rats, a), b), c) and d); Normal control, native P. extract, Ag-P. nano-extract and ZnO-P. nano-extract, respectively showing the normal architecture of hepatic tissue. e) and f) TAA treated, showing marked portal fibrosis associated with bridging fiboblasts and encircled the hepatocytes (FB), hyperplasia of the epithelial lining bile duct (HP), newly formed bile ductules (NB), and hydropic degeneration of hepatocytes (HD). g) TAA + native P. extract showing vacuolar degeneration of some hepatocytes (VD) and moderate fibrosis in the portal triad (FB). h) TAA + Ag-P. nano-extract showing scanty fibroblasts proliferation in the portal triad (FB). i) TAA + ZnO-P. nano-extract showing sparsely hepatocellular vacuolar degeneration (VD). 


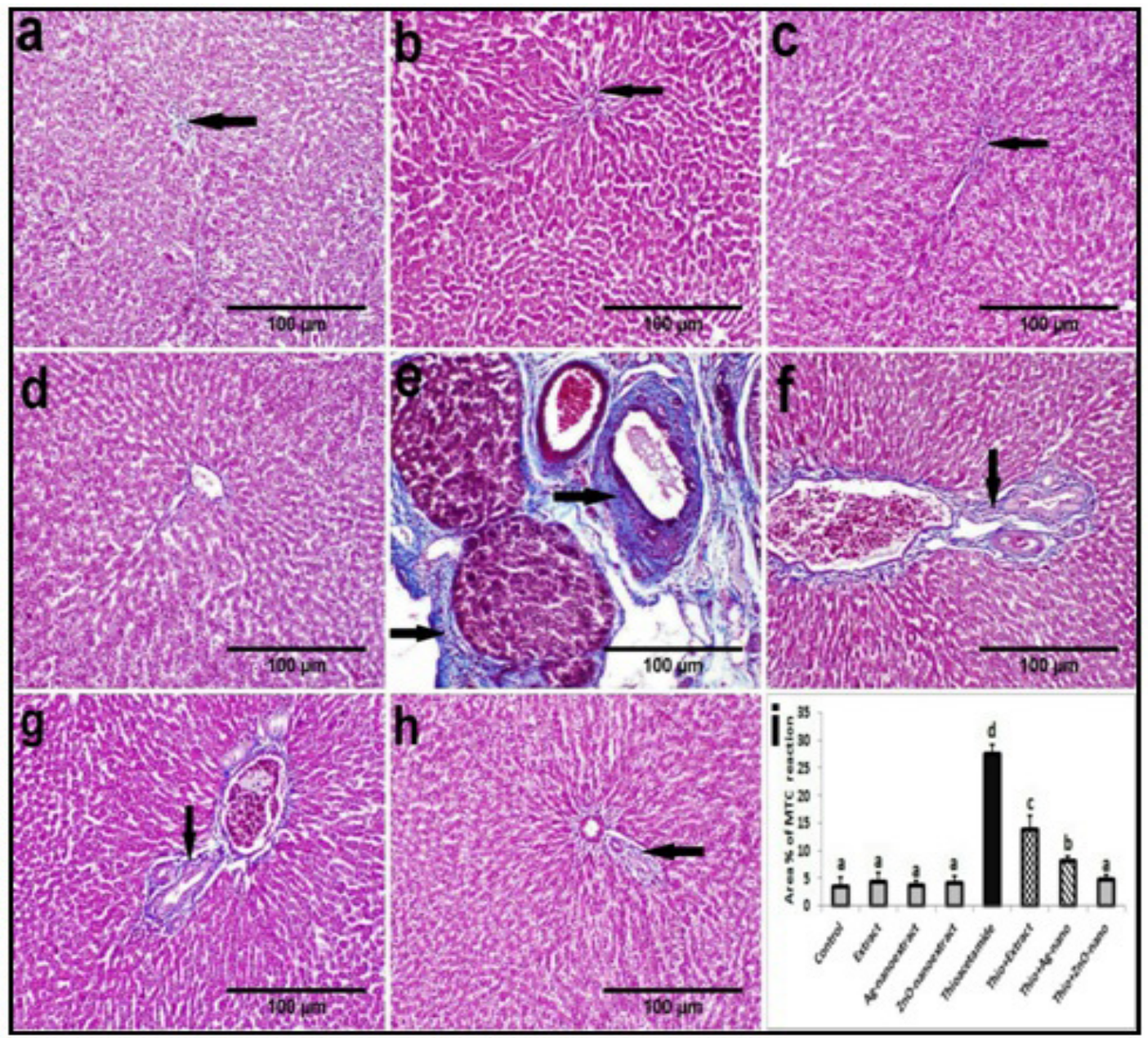

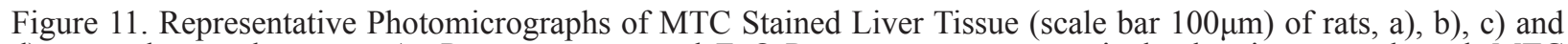
d); normal control, extract, Ag-P. nano-extract and ZnO-P. nano-extract, respectively showing normal weak MTC reaction. e) TAA treated showing strong positive blue reaction in the portal triad and around the hepatic lobules (arrows). f) TAA + native P. extract showing moderate histochemical reaction (arrow). g) TAA + Ag-P. nano-extract showing mild collagen deposition (arrow). h) TAA + ZnO-P. nano-extract showing normal weak MTC reaction in the portal triad (arrow). i) showing MTC staining area (\%) of collagen deposition. Data are shown as mean \pm SD; One-way analysis of variance was used for data analysis, mean values with unlike superscript letters were different significantly at $\mathrm{P} \leq 0.05$.

was agreed with Lakshmanan et al. (2018) and Moustafa et al. (2018). All peaks obtained by the XRD diffraction pattern are consistent with a polycrystalline Wurtzite structure of $\mathrm{ZnO}-\mathrm{NPs}$ and this was in accordance with Abdel-Rahman et al. (2021). Shape, size, morphology, and diffraction lattice of the fabricated nanomaterials were identified by TEM that was used for determining the diameter of whole particles on TEM images. Data that were obtained by TEM confirmed Ag-NPs synthesis. This was in agreement with the findings of the experiment performed by Ahmed and Ikram (2015) and supported by Aboulthana et al. (2019). Furthermore, the TEM data that supported the synthesis of ZnO-NPs agreed with the study performed by Khoshhesab et al. (2011). Decreasing the size of the $\mathrm{ZnO}-\mathrm{NPs}$ is strongly related to increasing their functionality as anticancer agents due to increasing the surface-to-volume ratio (Supatutkul et al., 2017; Azizi et al., 2017). DLS is categorized as a non-destructive technique that was used to determine the average diameter as well as distributions of the prepared M-NPs dispersed in aqueous solutions. Particles sizes of the synthesized M-NPs that were examined by DLS were larger than the ones obtained from TEM. This might be attributed to the effect of Brownian motion and the M-NPs agglomeration. In addition, the presence of secondary metabolites as a capping or reducing agent increases the stability of the synthesized M-NPs (Youssef et al., 2014).

The in vitro biological activity of aqueous Purslane extract before and after incorporating $M-N P S$

During the current study, it was noticed that incorporation of $\mathrm{ZnO}-\mathrm{NPs}$ into P. extract increased the antioxidant activity significantly $(\mathrm{P}<0.05)$ more than Ag-NPs. This was in agreement with Rajeshkumar et al. (2019) and supported recently by Stanisavljević et al. (2020) who were conducted to assess the in vitro antioxidant potential of plant-synthesized NPs and reported that the biogenic $\mathrm{ZnO}-\mathrm{NPs}$ exhibited higher antioxidant potential due to increasing concentration of the active phyto-constituents that possess redox potential. It was found that both of the Ag-and $\mathrm{ZnO}-\mathrm{P}$. nano-extracts exhibited a significant $(\mathrm{P}<0.05)$ higher inhibitory effect than that in native $P$. extract. This was in accordance with Vasudeo and Pramod (2016) and Thiruvengadam 
et al. (2019) who conducted on several classes on NPs and suggested that the bio-based $\mathrm{ZnO}-\mathrm{NPs}$ can exhibit an inhibitory effect on $\alpha$-amylase activity and therefore they might be studied as an alternative therapeutic agent for diabetes treatment. ZnO-P. nano-extract showed a significant $(\mathrm{P}<0.05)$ inhibitory effect on $\mathrm{AChE}$ activity higher than that in Ag-P. nano-extract and the extract itself. This was in agreement with Wang et al. (2009) who proposed that the M-NPs exhibited their inhibitory effect primarily by adsorption or interaction with $\mathrm{AChE}$ protein due to their binding affinity to ChEs and this attributed to the NPs' lipophilicity / or due to hydrophobicity of the enzyme environment in ChE molecules. So far, the mechanism by which the M-NPs interact with ChEs proteins is not completely understood.

It was noticed that the Ag-P. nano-extract exhibited the highest cytotoxic activity against $\mathrm{CACO}-2$ cells compared to $\mathrm{ZnO}$-nano-extract and native extract itself. This agreed with Duran et al. (2015) who postulated that the Ag-NPs have distinct physico-chemical and biological properties exceptionally small size and potential antibacterial activity. AgNO3 is the most commonly used Ag precursor because it is affordable and cheap (Balaz et al., 2017). The size and shape of the Ag-NPs are the key factors affecting the potential biological activity. They are characterized by a larger surface area that offers many opportunities for interaction with biomolecules. Thus, the triangular Ag-NPs with smaller sizes are more active than spherical and rod-shaped ones (Nam et al., 2015). The cytotoxic activity of Ag-NPs might be attributed to the presence of a negligible amount of free Ag ions obtained from $\mathrm{AgNO} 3$ that was used as a source of silver ions (Kim et al., 2009). Results of the previous studies revealed that the cells treated with $\mathrm{Ag}$ have limited exposure to $\mathrm{Ag}$ ions $(+)$, despite the $\mathrm{Ag}(+)$ release in cell cultures. Cytotoxicity of the Ag-NPs was comparable with that of $\mathrm{Ag}$ ions (+) and it occurs primarily as a result of the intracellular oxidative stress and it does not depend on the toxicity of $\mathrm{Ag}(+)$ (Yen and Mashitah, 2013). The potential role of the Ag-NPs with the particle size ranged from $15-55 \mathrm{~nm}$ in the initiation of oxidative stress was studied and it was noticed that exposure of cells to Ag-NPs exhibited abnormal changes in terms of morphology and absorption characteristics after 24 hours and hence the viability declined significantly with raising the Ag-NPs dose (Manna et al., 2001).

The ZnO-P. nano-extract exhibited the highest cytotoxic activity HEPG-2. This was in agreement with the studies suggested by De Angelis et al. (2013) and supported by Namvar et al. (2015) who mentioned that $\mathrm{ZnO}-\mathrm{NPs}$ exhibited cytotoxic activity on different human cell lines including hepatocytes and alveolar adenocarcinoma depending mainly on their particle size. Their cytotoxic activity is related to the ionization of $\mathrm{Zn}$ to $\mathrm{Zn} 2+$ and the production of free radicals from the NPs' surface resulting in an ionic and metabolic imbalance in the cell. Size, surface characteristics (e.g., surface charge and rugosity), dissolution, solubility, chemical reactivity and the exposure routes are directly correlated to the cytotoxic activity of $\mathrm{ZnO}-\mathrm{NPs}$. The nanotoxicological behavior of $\mathrm{ZnO}-\mathrm{NPs}$ was influenced after their interaction with biomolecules ( $\mathrm{Hu}$ et al., 2009). Solubility of the metal/metal oxide NPs is related to solution $\mathrm{pH}$ and temperature. The soluble $\mathrm{ZnO}-\mathrm{NPs}$ exhibited higher cytotoxic activity than insoluble ones when applied at the same concentration (Chang et al., 2012). Zinc belongs to the essential compounds that were utilized in the synthesis of DNA and protein, in addition to its vital role in blood coagulation and the immune system (Lye et al., 2012). The chemical reactivity and level of transparency of the $\mathrm{ZnO}-\mathrm{NPs}$ increase with decreasing their particle size with respect to the bulk-sized $\mathrm{ZnO}$. The biological activity of the $\mathrm{ZnO}-\mathrm{NPs}$ that is concerned with the cellular uptake and efficient delivery to biological systems was attributed to their unique features that increase the proportion of atoms on their surfaces and hence their potential toxicity increased. Although many studies have been conducted on the toxicity of the $\mathrm{ZnO}-\mathrm{NPs}$ on different human cell lines, safety approaches regarding their biological applications should be taken into consideration (Yang et al., 2009). The ZnO-NPs belong to popular nanomaterials that are characterized by their unique properties including cellular uptake and the delivery efficiency to biological systems (Mohammad et al., 2019). The ZnO-P. nano-extract showed cytotoxic activity against HEPG-2 cells due to the effect of the phyto-constituents that exert their biological activities including regulation of cell proliferation, phagocytosis, and intracellular signaling that stimulated by the production of the Reactive Oxygen Species (ROS) (Ibrahim et al., 2011). The $\mathrm{ZnO}$ nanostructures can be utilized for the development of anti-tumor agents due to their ability to fight cancer cells. In addition, they are dramatically less toxic to normal cells (Wahab et al., 2014; Moghaddam et al., 2017).

The HEPG-2 is characterized as a progressive development of preneoplastic and neoplastic lesions. It can be classified as one of the most prevalent malignant diseases (Feo et al., 2016). Casp3 is one of the executioner caspase members and $\mathrm{Bcl} 2$ belongs to the apoptotic genes. Regulation of the cell cycle was closely correlated apoptosis. Therefore, the absence of the apoptotic systems and uncontrolled cell proliferation can lead to tissue malignancies and growth disorders (Basu and Haldar, 1998). The ratio of the cell cycle phase was measured with PI staining using flow cytometry to reveal the antiproliferative activity of $\mathrm{ZnO}-\mathrm{P}$. nano-extract that was triggered by cell cycle arrest. As shown in Figure 5b, treatment of HEPG-2 with $\mathrm{ZnO}-\mathrm{P}$. nano-extract enhanced the accumulation of the cells at the $\mathrm{S}$ and Pre-G1 phases compared with the control HEPG-2 or those cells treated with the native extract itself. The percentage of the HEPG-2 cells at the S and Pre-G1 phases was about 52.92 and $33.82 \%$, respectively. On contrary, the $\mathrm{ZnO}-\mathrm{P}$. nano-extract decreased the HEPG-2 cells accumulation as compared to control HEPG-2 or those cells treated with the native extract itself at G2/M phase where their percentage at that phase was about $2.76 \%$.

In the present study, it was found that treatment of HEPG-2 with ZnO-NPs induced apoptosis as compared to control HEPG-2 or those cells treated with native extract itself. This was in agreement with Mohammad et al. (2019) who suggested reported that the presence of $\mathrm{ZnO}-\mathrm{NPs}$ 
exhibited antitumor activity confirmed by enhancing expression of the apoptotic genes that consequently lead to apoptosis induction in HEPG-2 cells. This type of NPs exhibited strong preferential cytotoxic activity against different types of human cancer cells including human bronchial epithelial BEAS-2B and human lung adenocarcinoma A549 in addition to HEPG-2 (Akhtar et al., 2012). During the current study, it was found that the $\mathrm{ZnO}-\mathrm{P}$. nano-extract exhibited a higher significant cytotoxic effect on HEPG-2 and this agreed with Jacob et al. (2014) and supported by Bisht and Rayamajhi (2016) who postulated that the cytotoxicity of ZnO-NPs might be attributable to the intracellular release of dissolved zinc ions that were accompanied by induction of ROS. This action is stimulated by comprising the pro-inflammatory reaction against $\mathrm{ZnO}-\mathrm{NPs}$ in the cell. Furthermore, the characteristic surface of the ZnO-NPs enables them to act as a redox system (Rasmussen et al., 2010).

The in vivo biological activity of aqueous Purslane extract before and after incorporating $M$-NPs

The ZnO-P. nano-extract was safer than Ag-P. nanoextract and the native extract itself when administrated orally. This was in agreement with $\mathrm{Ng}$ et al. (2017) who postulated that ingestion of $\mathrm{ZnO}-\mathrm{NPs}$ showed no toxicity in rodents although this type of NPs is well known by their ability to induce oxidative stress and production of excessive ROS. Safety of the nano-extract might refer to the role of the renal clearance to remove the NPs from the body with minimal degradation rate to avoid the possible side effects (Aboulthana et al., 2019 ; Abdel-Halim et al., 2020).

In the present study, it was found that TAA caused a significant $(\mathrm{P} \leq 0.05)$ reduction in the final total body weight. This was in agreement with Kabiri et al. (2014). This might be attributed to increasing lipolysis and protein catabolism with decreasing appetite (Hamed et al., 2011), absorption of the nutrients, utilization of food or excessive water and salts in addition to loss of proteins due to renal injury (Chiu, 2012). In addition, the decrease in liver weight in TAA treated group agreed with Algandaby et al. (2017) who added that the elevation in the liver index (ratio of liver/body weight) might refer to an accumulation of the ECM in the fibrotic liver. The ZnO-P. nano-extract showed an ameliorative effect by restoring the body and liver weights to normal values and this agreed with Wang et al. (2016) who mentioned that the ZnO-NPs might partly contribute to the increases in the relative organ weights due to the role of $\mathrm{Zn}$ in metabolic pathways in the small intestine and hence accumulated in the liver tissues.

During the present study, the significant $(\mathrm{P} \leq 0.05)$ reduction in levels of $\mathrm{RBCs}$ indices with increasing in WBCs count in TAA treated group agreed with Chen et al. (2008) who postulated that elevation of the WBCs count was related to inducing the inflammation that consequently leads to lowering the RBCs indices. The ZnO-P. nanoextract ameliorated the hematological measurements by restoring their levels to normalcy. This was following Shkal et al. (2020a) who postulated that the presence of $\mathrm{ZnO}-\mathrm{NPs}$ ameliorated the hematological toxicity induced by the toxic substances.

The elevation in activities of the hepatic enzymes in sera of TAA treated group might be attributed to damage of the cell membrane and hence these enzymes liberated into circulation (Ali et al., 2016). In addition, the elevation in bilirubin level might refer to the inflammatory and fibrotic effect of TAA that leads to blockage of bile ductile in portal triads and/or due to regurgitation of conjugated bilirubin from necrotic hepatocytes to sinusoids (Ahmed, 2001). The ZnO-P. nano-extract restored activities of the hepatic specific enzymes to normal levels. This was in accordance with Dawei et al. (2009) who suggested that ZnO-NPs are able to protect the integrity of the cell membranes against the damage induced by oxidative stress, increase levels of the antioxidants and decrease products of the peroxidation reactions. The pathological changes were ameliorated by treatment with $\mathrm{ZnO}-\mathrm{P}$. nano-extract due to lowering products of the lipid and protein peroxidation reactions, enhancement of antioxidant enzymes (SOD and CAT), and preserving the tissue GSH.

Also, TAA decreased levels of T. protein and albumin significantly $(\mathrm{P} \leq 0.05)$. This might refer to damage and worsening of the hepatic functions that consequently leads to suppressing detoxification of the hepatic functions (Yang et al., 2019). Although the native P. extract and its Ag-nano-extract opposed the deleterious effect of TAA indicating improvement of liver functions, $\mathrm{ZnO}-\mathrm{P}$. nano-extract restored the hepatic functions to a normal physiological state. The significant $(\mathrm{P} \leq 0.05)$ elevation in levels of TC and T.Gs in sera of TAA treated group agreed with Esteban et al. (1999) who emphasized that the liver plays a central role in lipid metabolism. The hepatic injury leads to changes in serum lipids, lipoprotein, TC, TGs, and activities of some related enzymes (Arranz et al., 1996). Therefore, Levels of the TC and T.Gs increased as a result of the hepatic injury induced by TAA. The $\mathrm{ZnO}-\mathrm{P}$. nano-extract decreased levels of the lipid measurements to normalcy and this was in agreement with Shkal et al. (2020)b who reported that ZnO-NPs prevented changes in lipids measurements due to their antioxidant characters.

It was postulated that oxidative stress is considered a major molecular mechanism involved in liver fibrosis induced by TAA. The ROS in addition to other toxic metabolites were released as a result of the hepatic metabolism of TAA leading to hepatic necrosis, centrilobular damage affecting cell membranes releasing the lipid peroxidation product (Tsai et al., 2010; Ryu et al., 2019).

During the current study, it was found that the activities of the antioxidants enzymes (SOD and CAT), levels of TAC and GSH decreased significantly $(\mathrm{P} \leq 0.05)$ in the TAA treated group that showed elevation in products of the peroxidation reactions (LPO and TPC) in liver tissue homogenate. This was in accordance with Lochner et al. (2009) who emphasized that TAA enhanced oxidative stress due to activation of neutrophils, macrophage, and monocytes which release various pro-oxidants. Due to the presence of a thiono-sulfur group, the TAA was metabolized extensively to produce acetamide and TAA-S-oxide then consequently transformed into 
TAA-S, S-dioxide, and unstable reactive metabolites that bind covalently to liver macromolecules initiating necrosis (Chilakapati et al., 2005). The ZnO-P. nanoextract restored the antioxidant status to normalcy by elevating levels of the antioxidants (SOD, CAT, and GSH) with decreasing levels of the peroxidation products in hepatic tissues. This agreed with Nagajyothi et al. (2015) and $\mathrm{Li}$ et al. (2017) who reported that the $\mathrm{ZnO}-\mathrm{NPs}$ exhibited antioxidant and anti-inflammatory properties. Furthermore, the presence of Zinc is considered as a core constituent of antioxidant enzymes and it exerts antioxidant activity by various mechanisms as regulation of cellular glutathione, induction of metallothioneins, a powerful scavenger of free radicals, protection sulphhydryl groups against oxidation, keeping the intracellular GSH levels and reducing the peroxidation products (Bao et al. 2013). Also, the concentration of the peroxidation products decreased as a result of $\mathrm{ZnO}$-P. nano-extract administration more than Ag-P. nano-extract due to the efficiency of $\mathrm{Zn}$ (a powerful antioxidant metal) in displacing transition metals (iron and copper) from catalytic sites (Afifi and Abdelazim, 2015). ROS production is strongly related to and inflammation and fibrosis in many hepatic diseases. Both oxidative stress and inflammatory mediators play an important role in the activation of the HSCs that consequently inhibited antioxidant defense and hence enhance generation of ROS and inflammation during induction of liver fibrosis (Lavieri et al., 2014). TAA injection caused marked hepatocytes necrosis, lymphocyte infiltration, and fibroblasts proliferation. Upon liver injury, the HSCs acquire a highly proliferative index producing fibrillar collagen within the injured liver (Elsharkawy et al., 2005). It was demonstrated that the antioxidant agents that exhibit anti-inflammatory effect are considered promising factors for attenuating the hepatic fibrosis that was promoted by TNF- $\alpha$ and IL-6 (Li et al., 2016 ; Kakino et al., 2018). Therefore, TNF- $\alpha$ and IL- 6 signal pathways have been studied during this present study. The anti-fibrotic mechanism of P. extract and its $\mathrm{Ag}$ - and $\mathrm{ZnO}-\mathrm{P}$. nano-extracts were evaluated by assaying the proinflammatory cytokines (TNF- $\alpha$ and IL-6) that were studied as inflammatory markers in liver tissue homogenates as suggested by Racanelli and Rehermann (2006) who reported that levels of these cytokines are related to ROS overproduction. The $\mathrm{ZnO}-\mathrm{P}$. nano-extract was found to suppress the accumulation of oxidative and inflammatory markers and restore antioxidative status by increasing levels of the antioxidants with decreasing markers of the oxidative stress showing strong antioxidant and anti-inflammatory activity opposing the adverse effect of TAA. Also, the anti-inflammatory effect of ZnO-P. nano-extract was explored by lowering levels of TNF- $\alpha$ and IL- 6 . It mitigated the elevation in TNF- $\alpha$ and IL- 6 stimulated by TAA injection. TNF- $\alpha$ is involved in the pathogenesis of various inflammatory liver diseases (Dong et al. 2016). IL-6 was highly specific in a diagnosis of non-alcoholic steatohepatitis because it was strongly related to fatty liver disease (Tarantino et al. 2009). Both TNF- $\alpha$ and IL- 6 levels increased in the sera as a result of acute or chronic hepatitis infection (Xia et al. 2015).
Since IL-6 dysregulates enzymatic antioxidant defenses, it was suggested that $\mathrm{ZnO}-\mathrm{NPs}$ might protect hepatic tissues against the lesion induced by TAA via reducing levels of IL-6 and lipid peroxidation (Mathy-Hartert et al. 2008). Hydroxyproline is one of the most amino acids present in collagen following hydroxylation of proline moiety. It is produced in the ECM by activation of HSCs to preserve the integrity and function of the hepatocytes (Gabr et al., 2017). Its level in liver tissues comprises a superior limiting factor which could signify correct rates and progression of liver fibrogenesis (Wynn, 2008). Development of hepatic fibrosis depends mainly on the incorporation of proline into procollagen via hydroxylation process to the hydroxyproline that is correlated with rates of collagen synthesis and can be used in the assessment of collagen content. Therefore, the level of this amino acid is considered a marker of collagen metabolism (synthesis and degradation) during the pathogenesis of hepatic fibrosis (McAnulty et al., 1991). During the current study, the hydroxyproline content increased significantly $(\mathrm{P} \leq 0.05)$ in TAA treated group and this agreed with Eissa et al. (2018) and was supported recently by Yang et al. (2019) who demonstrated that the level of hydroxyproline increased as a result of inhibition of the TGF-b/a-SMA signaling pathway that attenuates liver fibrosis. The ZnO-P. nano-extract exhibited anti-fibrotic activity due to its activity in downregulating the hydroxyproline (fibrotic marker). This was in agreement with Szuster-Ciesielska et al. (2009) who reported that the presence of $\mathrm{ZnO}-\mathrm{NPs}$ inhibited the development of liver fibrosis by reducing the hepatic hydroxyproline level. Also, zinc exhibited its antioxidant and ameliorative role by inhibiting ethanol and acetaldehyde-induced activation of HSCs and hence inhibits markers of HCS activation.

\section{Histopathological investigation}

During the present study, it was noticed that injection of TAA caused severe hepatic fibrosis in addition to the abnormalities that detected histopathologically and this might refer to the vascular congestion and leukocyte infiltrations that induced as a result of the inflammatory changes and consequently lead to liver fibrosis (Jeon et al., 2003; Amalia et al., 2007). Hepatic fibrosis might occur due to effect of the oxidative stress is considered the most common cause of liver injury (Poli, 2000). Administration of ZnO-P. nano-extract caused marked regression in the alterations demonstrated histopathologically and this might be attributed to the efficiency of ZnO-NPs to enhance the antioxidant status by lowering levels of the free radicals with increasing activities of the antioxidases (Badkoobeh et al., 2013).

\section{Histochemical investigation (MTC stain for collagen)}

The histochemical examination showed that liver tissues of rats treated with TAA were noticed with a strong positive blue MTC reaction in the portal triad. This was following Bissell et al. (1990) who demonstrated that collagen accumulated in hepatic tissues (mark of fibrosis) and this might be attributed to the oxidative stress that stimulates inflammation and the pro-inflammatory 
cytokines, chemokines, and adhesion molecules that can initiate activation of the HSC (Pinzani and MaciasBarragan, 2010). Poonkhum et al. (2011) added that overproduction of collagens occurred as a result of HSCs activation during hepatic fibrosis. Therefore, the MTC used for staining thick collagen fibers to be detected in liver sections of the TAA treated group. Administration of ZnO-P. nano-extract showed a normal histochemical reaction. This was supported by Sorensen-Zender et al. (2015) who emphasized that the presence of ZnO-NPs decreased products of the peroxidation reactions which participate in fibrosis development in the hepatic tissues and consequently can control fibrosis. Moreover, zinc exhibited an effective role in the protection of the liver against fibrosis decreasing the transforming growth factor beta that induced fibroblast activation and epithelial differentiation (features of tissue fibrosis).

In conclusion, the Ag- and $\mathrm{ZnO}$ - NPs were selected to be incorporated into $\mathrm{P}$. extract due to their impressive properties. It was noticed that the $\mathrm{ZnO}-\mathrm{P}$. nano-extract exists with higher concentrations of total polyphenolic compounds and condensed tannins and hence with higher TAC, iron reducing power, and scavenging activity with respect to the Ag-P. nano-extract and native extract itself. Both of Ag- and $\mathrm{ZnO}-\mathrm{P}$. nano-extract have the same inhibitory effect on $\alpha$-amylase. As regards AChE activity, the ZnO-P. nano-extract exhibited a higher inhibitory effect than Ag-P. nano-extract. On contrary, the Ag-P. nano-extract showed the highest cytotoxic activity (IC50 $310.70 \mu \mathrm{g} / \mathrm{mL}$ ) against CACO-2 cells while the $\mathrm{ZnO}-\mathrm{P}$. nano-extract exhibited the highest cytotoxic activity (IC50 $242.20 \mu \mathrm{g} / \mathrm{mL}$ ) against HEPG-2 cells as compared to the native extract. Therefore, $\mathrm{ZnO}$-P. nano-extract was evaluated against the cell cycle and apoptosis of HEPG-2 cells and compared to the native extract. It was found that $\mathrm{ZnO}-\mathrm{P}$. nano-extract was safer and exhibited an ameliorative effect against the hepatic fibrosis induced by TAA in addition to its ability to restore the histopathological architecture of the liver tissue more than Ag-P. nano-extract and the native extract itself.

\section{Recommendation}

Although the incorporation of Ag-NPs into the different plant extracts enhanced their biological activities and exhibited an ameliorative effect against various chronic diseases, the recent studies demonstrated that it exerts an adverse effect on brain tissues that being considered as the most organ susceptible to the NPs deposition. Therefore, the researchers must undergo further studies for revealing the effect of $\mathrm{ZnO}$-plant nano-extract on that tissue.

\section{Author Contribution Statement}

W.M.A. proposed the scientific idea and collected all papers published previously and related to that idea. W.M.A. and N.I.O. were responsible for preparing the plant extract. W.M.A., N.I.O. and E.A.H. performed the experimental work and provided reagents/materials necessary for experiments. A.M.Y. was concerned with preparing silver plant nano-extracts. W.M.A. and E.A.H. were responsible for undergoing the in vitro study. W.M.A., N.I.O. and K.A.A. were responsible for carrying out the practical work on experimental animals. K.A.A. was concerned with carrying out the histopathological examination. All authors read and approved the final manuscript.

\section{Acknowledgements}

This study was accomplished practically in laboratories of the National Research Centre, Dokki, Giza, Egypt and provided by researchers of different scientific fields.

\section{Ethical statement}

The experimental design and animals handling were carried out based on a protocol approved by the Institutional Animal Ethical Committee of National Research Centre, Dokki, Giza, Egypt, and according to guidelines reported in "Guide for the care and use of laboratory animals".

\section{Conflict of interest}

The authors certify that there were no declared financial or non-financial conflicts of interest among them.

\section{References}

Abdel-Halim AH, Fyiad AA, Aboulthana WM, et al (2020). Assessment of the anti-diabetic Effect of Bauhinia variegata gold nano-extract against streptozotocin induced diabetes mellitus in rats. $J$ Appl Pharma Sci, 10, 077-091.

Abdel-Rahman M, Ibrahim H, Mostafa MYA, et al (2021). The characterization of $\mathrm{ZnO}$ nanoparticles by applying x-ray diffraction and different methods of peak profile analysis. Physica Scripta, 96, 095704.

Aboulthana WM, Youssef AM, El-Feky AM, et al (2019). Evaluation of antioxidant efficiency of Croton tiglium L. seeds extracts after incorporating silver Nanoparticles. Egypt J Chem, 62, 181-200.

Aebi H (1984). Catalase in vitro. Methods Enzymol, 105, 121-6. Afifi M, Abdelazim AM (2015). Ameliorative effect of zinc oxide and silver nanoparticles on antioxidant system in the brain of diabetic rats. Asian Pac J Trop Biomed, 5, 874-7.

Ahmed OM (2001). Histopathological and biochemical evaluation of liver and kidney lesions in streptozotocin diabetic rats treated with glimepiride and various plant extracts. J Union Arab Biol Cairo A Zool, 16, 585-625.

Ahmed S, Ikram S (2015). Synthesis of gold nanoparticles using plant extract: An overview. Nano Res Appl, 1, 1-64.

Akhtar MJ, Ahamed M, Kumar S, et al (2012). Zinc oxide nanoparticles selectively induce apoptosis in human cancer cells through reactive oxygen species. Int J Nanomedicine, 7, 845-57.

Al-Attar AM (2010). Physiological effects of some plant oils supplementation on streptozotocin-induced diabetic rats. Merit Res J Med Med Sci, 5, 55-71.

Al-Attar AM, Al-Rethea HA (2017). Chemoprotective effect of omega-3 fatty acids on thioacetamide induced hepatic fibrosis in male rats. Saudi J Biol Sci, 24, 956-65.

Algandaby MM, Breikaa RM, Eid BG, et al (2017). Icariin protects against thioacetamide-induced liver fibrosis in rats: Implication of anti-angiogenic and anti-autophagic properties. Pharmacol Rep, 69, 616-24.

Ali SI, Said MM, Hassan EK (2011). Prophylactic and curative effects of purslane on bile duct ligation-induced hepatic 
fibrosis in albino rats. Ann Hepatol, 10, 340-6.

Ali SO, Darwish HA, Ismail NA (2016). Curcumin, silybin phytosome ${ }^{\circledR}$ and a-R-lipoic acid mitigate chronic hepatitis in rat by inhibiting oxidative stress and inflammatory cytokines production. Basic Clin Pharmacol Toxicol, 118, 369-80.

Amalia PM, Possa MN, Augusto MC, et al (2007). Quercetin prevents oxidative stress in cirrhotic rats. Dig Dis Sci, 52, 2616-21.

Anusha M, Venkateswarlu M, Prabhakaran V, et al (2011). Hepatoprotective activity of aqueous extract of Portulaca oleracea in combination with lycopene in rats. Indian $J$ Pharmacol, 43, 563-7.

Arnao MB, Cano A, Acosta M (2001). The hydrophilic and lipophilic contribution to total antioxidant activity. Food Chem, 73, 239-44.

Arranz MI, Lasuncion ML, Perales J, et al (1996). Fatty acids composition of lipoprotein lipids in hepatobiliary diseases. Eur J Clin Chem Clin Biochem, 34, 701-9.

Arruda SF, Siqueira EM, Souza EM (2004). Malanga (Xanthosoma sagittifolium) and Purslane (Portulaca oleracea) Leaves Reduce Oxidative Stress in Vitamin A Deficient Rats. Ann Nutr Metab, 48, 288-95.

Azizi S, Mohamad R, Shahri MM (2017). Green microwaveassisted combustion synthesis of Zinc Oxide nanoparticles with Citrullus colocynthis (L.) Schrad: Characterization and Biomedical Applications. Molecules, 22, 301-14.

Azuka OI, Mary A, Abu OL (2014). A review on Portulaca oleracea (Purslane) plant - its nature and biomedical benefits. Int J Biomed Res, 5, 70-80.

Badkoobeh P, Parivar K, Kalantar SM, et al (2013). Effect of nano-zinc oxide on doxorubicin-induced oxidative stress and sperm disorders in adult male Wistar rats. Iran J Reprod Med, 11, 355-64.

Balaz M, Balazova L, Daneu N, et al (2017). Plant-mediated synthesis of silver nanoparticles and their stabilization by wet stirred media milling. Nanoscale Res Lett, 12, 83.

Bao B, Ahmad A, Azmi A, et al (2013). The biological significance of zinc in inflammation and aging. In: Inflammation, Advancing age and Nutrition: Research and Clinical Interventions, 1st ed. Edited by Rahman, I., Bagchi ,D. New York, NY., Elsevier Inc, Chapter 2, PP 15-27.

Bao SJ, Lei C, Xu MW, et al (2012). Environment-friendly biomimetic synthesis of $\mathrm{TiO} 2$ nanomaterials for photocatalytic application. Nanotechnology, 23, 205601.

Basu A, Haldar S (1998). The relationship between BcI2, Bax and p53: consequences for cell cycle progression and cell death. Mol Hum Reprod, 4, 1099-1109.

Beutler E, Duron O, Kelly BM (1963). Improved method for the determination of blood glutathione. J Lab Clin Med, 61, 882-8.

Bisht G, Rayamajhi S (2016). ZnO Nanoparticles: A Promising Anticancer Agent. Nanobiomedicine (Rij), 3, 9-20.

Bissell DM, Friedman SL, Maher JJ, et al (1990). Connective tissue biology and hepatic fibrosis: report of a conference. Hepatology, 11, 488-98.

Broadhurst RB, jones WT (1978). Analysis of condensed tannins using acidified vanillin. $J$ Sci Food Agri, 48, 788-94.

Chang YN, Zhang M, Xia L, et al (2012). The toxic effects and mechanisms of $\mathrm{CuO}$ and $\mathrm{ZnO}$ nanoparticles. Materials (Basel), 5, 2850-71.

Chen TM, Subeq YM, Lee RP, et al (2008). Single dose intravenous thioacetamide administration as a model of acute liver damage in rats. Int J Exp Pathol, 89, 223-31.

Chilakapati J, Shankar K, Korrapati MC, et al (2005). Saturation toxicokinetics of thioacetamide: Role in initiation of liver injury. Drug Metab Disposit, 33, 1877-85.

Chiu CH (2012). Hepatoprotection of silymarin against thioacetamide-induced chronic liver fibrosis. J Sci Food Agric, 92, 1441-7.

Dagdeviren C, Hwang SW, Su Y, et al (2013). Transient, biocompatible electronics and energy harvesters based on ZnO. Small, 9, 3398-3404.

Dawei AI, Zhisheng W, Anguo Z (2009). Protective effects of Nano-ZnO on the primary culture mice intestinal epithelial cells in vitro against oxidative injury. J Anim Vet $A d v, \mathbf{8}$, 1964-7.

De Angelis I, Barone F, Zijno A, et al (2013). Comparative study of $\mathrm{ZnO}$ and $\mathrm{TiO}$ - nanoparticles: physicochemical characterisation and toxicological effects on human colon carcinoma cells. Nanotoxicol, 7, 1361-72.

Dong Y, Liu Y, Kou X, et al (2016). The protective or damaging effect of Tumor necrosis factor- $\alpha$ in acute liver injury is concentration-dependent. Cell Bioscience, 6, 1-10.

Dreaden EC, Alkilany AM, Huang X, et al (2012). The golden age: gold nanoparticles for biomedicine. Chem Soc Rev, 41, 2740-79.

Duran N, Silveira CP, Durán M, et al (2015). Silver nanoparticle protein corona and toxicity: a mini review. JNanobiotechnol, 13,55 .

Eidi A, Mortazavi P, Moghadam JZ, et al (2015). Hepatoprotective effects of Portulaca oleracea extract against CCl4-induced damage in rats. Pharm Biol, 53, 1042-51.

Eissa LA, Kenawy HI, El-Karef A, et al (2018). Antioxidant and anti-inflammatory activities of berberine attenuate hepatic fibrosis induced by thioacetamide injection in rats. Chem Biol Interact, 294, 91-100.

Elizabeth BM (2000). Grading and staging the histopathological lesions of chronic hepatitis: the knodell histology activity index and beyond. Hepatology, 31, 241-6.

Ellman GL, Courtney KD, Andres VJ, et al (1961). A new and rapid colorimetric determination of acetylcholinesterase activity. Biochem Pharmacol, 7, 88-95.

El-Nour KMMA, Eftaiha A, Al-Warthan A, et al (2010). Synthesis and applications of silver nanoparticles. Arab $J$ Chem, 3, 135-40.

Elsharkawy AM, Oakley F, Mann DA (2005). The role and regulation of hepatic stellate cell apoptosis in reversal of liver fibrosis. Apoptosis, 10, 927-39.

Engelmann H, Novick D, Wallach D (1990). Two tumor necrosis factor-binding proteins purified from human urine. Evidence for immunological cross-reactivity with cell surface tumor necrosis factor receptors. $J$ Biol Chem, 265, 1531-63.

Esteban FJ, Sánchez-López AM, Del Moral ML, et al (1999). Effect of thioacetamide and dexamethasone on serum lipids in rats fed on high-fat sunflower or olive oil diets. J Nutr Sci Vitaminol (Tokyo), 45, 231-8.

Fatimah I (2016). Green synthesis of silver nanoparticles using extract of Parkia speciosa Hassk pods assisted by microwave irradiation. JAdv Res, 7, 961- 9.

Feo F, Simile MM, Pascale RM (2016). Focal loss of long non-coding RNA-PRAL, as determinant of cell function and phenotype of hepatocellular carcinoma. Ann Transl Med, 4, 183.

Gabr SA, Alghadir AH, SherifYE, et al (2017). Hydroxyproline as a Biomarker in Liver Disease. In: Patel VB and Preedy VR (eds) Biomarkers in liver disease. Dordrecht: Springer, pp 471-91.

Gong F, Li F, Zhang L, et al (2009). Hypoglycemic effects of crude polysaccharides from Purslane. Int J Mol Sci, 10, 880-8.

Green L, Wagner D, Glogowski J, et al (1982). Analysis of nitrate, nitrite and $[15 \mathrm{~N}]$ nitrate in biological fluids. Anal Biochem, 126, 131-8.

Greenwel P, Domı'nguez-Rosales JA, Mavi G, et al (2000). 
Hydrogen peroxide: a link between acetaldehyde-elicited alpha1(I) collagen gene up-regulation and oxidative stress in mouse hepatic stellate cells. Hepatology, 31, 109-16.

Hamed GM, Bahgat NM, Abdel Mottaleb FI, et al (2011). Effect of flavonoid quercetin supplement on the progress of liver cirrhosis in rats. Life Sci $J, \mathbf{8}, 641-51$.

$\mathrm{Hu} \mathrm{X}$, Cook S, Wang P, et al (2009). In vitro evaluation of cytotoxicity of engineered metal oxide nanoparticles. Sci Total Environ, 407, 3070-2.

Ibrahim AY, Mahmoud K, El-Hallouty SM (2011). Screening of antioxidant and cytotoxicity activities of some plant extracts from Egyptian flora. J Appl Sci Res, 7, 1246-58.

Jacob SJP, Bharathkumar R, Ashwathram, G. (2014). Aspergillus niger mediated synthesis of $\mathrm{ZnO}$ nanoparticles and their antimicrobial and in vitro anticancerous activity. WJPR, 3, 3044-54.

Jeon TI, Hwang SG, Park NG, et al (2003). Antioxidative effect of chitosan on chronic carbon tetrachloride induced hepatic injury in rats. Toxicology, 187, 67-73.

Kabiri N, Darabi MA, Rafieian-Kopaei M, et al (2014). Protective effect of kombucha tea on liver damage induced by thioacetamide in rats. $J$ Biol Sci, 14, 343-8.

Kakino S, Ohki T, Nakayama H, et al (2018). Pivotal role of TNFalpha in the development and progression of nonalcoholic fatty liver disease in a murine model. Horm Metab Res, 50, 80-7.

Khoshhesab ZM, Sarfaraz M, Asadabad MA (2011). Preparation of $\mathrm{ZnO}$ nanostructures by chemical precipitation method. Synthesis and Reactivity in Inorganic, Metal-Organic and Nano-Metal Chemistry, 41, pp 814-9.

Kim SW, Kim KS, Lamsal K, et al (2009). An in vitro study of the antifungal effect of silver nanoparticles on oak wilt pathogen Raffaelea sp. J Microbiol Biotechnol, 19, 760-4.

Koopman G, Reutelingsperger CP, Kuijten GA, et al (1994). Annexin V for flow cytometric detection of phosphatidylserine expression on B cells undergoing apoptosis. Blood, 84, 1415-20.

Koracevic D, Koracevic G, Djordjevic V, et al (2001). Method for the measurement of antioxidant activity in human fluids. J Clin Pathol, 54, 356-61.

Lakshmanan G, Sathiyaseelan A, Kalaichelvan PT, et al (2018). Plant-mediated synthesis of silver nanoparticles using fruit extract of Cleome viscosa L.: Assessment of their antibacterial and anticancer activity. Karbala Int J Modern Sci, 4, 61-8.

Laleman W, Vander Elst I, Zeegers M, et al (2006). A stable model of cirrhotic portal hypertension in the rat: thioacetamide revisited. Eur J Clin Invest, 36, 242-9.

Lavieri R, Piccioli P, Carta S, et al (2014). TLR costimulation causes oxidative stress with unbalance of proinflammatory and anti-inflammatory cytokine production. J Immunol, 192, 5373-81.

Lee SH, Rho W-Y, Park SJ, et al (2018). Multifunctional selfassembled monolayers via microcontact printing and degasdriven flow guided patterning. Sci Rep, 8, 16763.

Levine RL, Williams JA, Stadtman ER, et al (1994). Carbonyl assays for determination of oxidatively modified proteins. Methods Enzymol, 233, 346-57.

Li J, Chen H, Wang B, et al (2017). ZnO nanoparticles act as supportive therapy in DSS- induced ulcerative colitis in mice by maintaining gut homeostasis and activating Nrf2 signaling. Sci Rep, 7, 1-11.

Li S, Hong M, Tan H-Y, et al (2016). Insights into the role and interdependence of oxidative stress and inflammation in liver diseases. Oxidative Medicine and Cellular Longevity, Vol. 2016, Article ID 4234061, 21 pages.

Lochner A, Marais E, Genade S, et al (2009). Protection of the ischaemic heart: Investigations into the phenomenon of ischaemic preconditioning. Cardiovasc J Afr, 20, 43-51.

Lye JC, Richards CD, Dechen K, et al (2012). Systematic functional characterization of putative zinc transport genes and identification of zinc toxicosis phenotypes in Drosophila melanogaster. J Exp Biol, 215, 3254-65.

Mamillapalli V, Atmakuri AM, Khantamneni P (2016). Nanoparticles for herbal extracts. Asian J Pharm, 10, 54-60.

Manna A, Imae T, Aoi K, et al (2001). Synthesis of dendrimerpassivated noble metal nanoparticles in a polar medium: comparison of size between silver and gold particles. Chem Mater, 13, 1674-81.

March CJ, Mosley B, Larsen A, et al (1985). Cloning, sequence and expression of two distinct human interleukin-1 complementary DNAs. Nature, 315, 641-7.

Mathy-Hartert M, Hogge L, Sanchez C, et al (2008). Interleukin$1 \mathrm{~b}$ and interleukin- 6 disturb the antioxidant enzyme system in Bovine chondrocytes : a possible explanation for oxidative stress generation. Osteoarthritis Cartilage, 16, 756-63.

McAnulty RJ, Moores SR, Talbot RJ, et al (1991). Long-term changes in mouse lung following inhalation of a fibrosisinducing dose of $239 \mathrm{PuO2}$ : changes in collagen synthesis and degradation rates. Int $J$ Radiat Boil, 59, 229-38.

Moghaddam AB, Moniri M, Azizi S, et al (2017). Eco-friendly formulated zinc oxide nanoparticles: induction of cell cycle arrest and apoptosis in the MCF-7 cancer cell line. Genes, 8, 281-96.

Mohammad GRKS, Seyedi SMR, Ehsan Karimi E, et al (2019). The cytotoxic properties of zinc oxide nanoparticles on the rat liver and spleen, and its anticancer impacts on human liver cancer cell lines. J Biochem Mol Toxicol, 2019, e22324.

Moustafa H, Darwish NA, Youssef AM, et al (2018). Highperformance of nanoparticles and their effects on the mechanical, thermal stability and UV-shielding properties of PMMA nanocomposites. Egypt J Chem, 61, 23-32.

Murdock RC, Braydich-Stolle L, Schrand AM, et al (2008). Characterization of nanomaterial dispersion in solution prior to in vitro exposure using dynamic light scattering technique. Toxicol Sci, 101, 239-53.

Nagajyothi PC, Cha SJ, Yang IJ, et al (2015). Antioxidant and anti-inflammatory activities of zinc oxide nanoparticles synthesized using Polygala tenuifolia root extract. $J$ Photochem Photobiol B Biol, 146, 10-7.

Nam G, Rangasamy S, Purushothaman B, et al (2015). The application of bactericidal silver nanoparticles in wound treatment. Nanomater Nanotechnol, 5, 23.

Namvar F, Rahman HS, Mohamad R, et al (2015). Cytotoxic effects of biosynthesized zinc oxide nanoparticles on murine cell lines. Evid Based Complement Alternat Med, Vol. 2015, Article ID 593014, 11 pages.

$\mathrm{Ng} \mathrm{CT}$, Yong LQ, Hande MP, et al (2017). Zinc oxide nanoparticles exhibit cytotoxicity and genotoxicity through oxidative stress responses in human lung fibroblasts and Drosophila melanogaster. Int J Nanomed, 12, 1621-17.

Nishikimi M, Rao NA, Yagi K (1972). The occurrence of superoxide anion in the reaction of reduced phenazine methosulphate and molecular oxygen. Biochem Biophys Res Comm, 46, 849-64.

Nouroozi F, Farzaneh F (2011). Synthesis and characterization of brush-like $\mathrm{ZnO}$ nanorods using albumen as biotemplate. $J$ Brazil Chem Soc, 22, 484-8.

Ohkawa H, Ohishi N, Yagi K (1979). Assay for lipid peroxides in animal tissues by thiobarbituric acid reaction. Anal Biochem, 95, 351-8.

Oyaizu M (1986). Studies on product of browning reaction prepared from glucose amine. Jpn J Nutr, 44, 307-15.

Paget GE, Barnes JM (1964). Toxicity tests. In: Laurance DR, Bacharach AL, editors. Evaluation of Drug Activities: 
Pharmacometrics, Vol 1. New York: Academic Press: pp 135-65.

Pfaffl MW (2001). A new mathematical model for relative quantification in real-time RT-PCR. Nucleic Acids Rese, 29, 45.

Pinzani M, Macias-Barragan J (2010). Update on the pathophysiology of liver fibrosis. Exp Rev Gastroenterol Hepatol, 4, 459-72.

Poli G (2000). Pathogenesis of liver fibrosis: role of oxidative stress. Mol Aspects Med, 21, 49-98.

Poonkhum R, Pradidarcheep W, Nilbu-Nga S, et al (2011). Distribution of hepatic myofibroblasts and type I and III collagen in rat liver cirrhosis induced by thioacetamide. Int J Morphol, 29, 501-8.

Prieto P, Pineda M, Aguilar M (1999). Spectrophotometric quantitation of antioxidant capacity through the formation of a phosphomolybdenum complex: Specific application to the determination of vitamin E. Anal Biochem, 269, 337-41.

Prow TW, Grice JE, Lin LL, et al (2011). Nanoparticles and microparticles for skin drug delivery. Adv Drug Deliv Rev, 63, 470-91.

Racanelli V, Rehermann B (2006). The liver as an immunological organ. Hepatology, 43, 54-62.

Rahman MM, Islam MB, Biswas $\mathrm{M}$, et al (2015). In vitro antioxidant and free radical scavenging activity of different parts of Tabebuia pallida growing in Bangladesh. BMC Res Notes, 8, 621-8.

Raja S, Ramesh V, Thivaharan V (2017). Green bio synthesis of silver nanoparticles using Calliandra haematocephala leaf extract, their antibacterial activity and hydrogen peroxide sensing capability. Arab J Chem, 10, 253-61.

Rajeshkumar S, Menon S, Kumar SV, et al (2019). Antibacterial and antioxidant potential of biosynthesized copper nanoparticles mediated through Cissus arnotiana plant extract. J Photochem Photobiol B, 197, 111531.

Rasmussen JW, Martinez E, Louka P, et al (2010). Zinc oxide nanoparticles for selective destruction of tumor cells and potential for drug delivery applications. Exp Opin Drug Deliv, 7, 1063-77.

Reddy GK, Enwemeka CS (1996). A simplified method for the analysis of hydroxyproline in biological tissues. Clin Biochem, 29, 225-9.

Reeves HL, Friedman SL (2002). Activation of hepatic stellate cells- a key issue in liver fibrosis. Front Biosci, 7, 808-26.

Ryu EH, Yang JS, Lee MJ, et al (2019). Antioxidant effects of kimchi supplemented with black raspberry during fermentation protect against liver cirrhosis-induced oxidative stress in rats. Nutr Res Pract, 13, 87-94.

Sahaa MR, Hasana SMR, Aktera R, et al (2008). In vitro free radical scavenging activity of methanol extract of the leaves of Mimusops elengi Linn. Bangl J Vet Med, 6, 197-202.

Seif MM, Madboli A, Marrez DA, et al (2019). Hepato-renal protective effects of Egyptian Purslane extract against experimental cadmium toxicity in rats with special emphasis on the functional and histopathological Changes. Toxicol Rep, 6, 625-31.

Shkal KEM, Attia AM, El-Banna SG, et al (2020)a. Ameliorating effect of zinc oxide nanoparticles against hematotoxicity induced by cyclophosphamide in male albino rats. $A d v$ Hematol Oncol Res, 3, 26-31.

Shkal KEM, Attia AM, El-Banna SG, et al (2020)b. Antidyslipidemic effect of zinc oxide nanoparticles against cyclophosphamide induced dyslipidemia in male albino rats. G Med Sci, 1, 55-63.

Shousha WG, Aboulthana WM, Salama AH, et al (2019). Evaluation of the biological activity of Moringa oleifera leaves extract after incorporating silver nanoparticles, in vitro study. Bull Nat Res Centre, 43, 212.

Singleton VL, Rossi JA (1965). Colorimetry of total phenolics with phosphomolybdic phosphotungstic acid reagents. $\mathrm{Am}$ J Enol Vitic, 16, 144-58.

Sonia S, Linda Jeeva Kumari H, Ruckmanib K, et al (2017). Antimicrobial and antioxidant potentials of biosynthesized colloidal zinc oxide nanoparticles for a fortified cold cream formulation: A potent nanocosmeceutical application. Mater Sci Eng C Mater Biol Appl, 79, 581-9.

Sorensen-Zender I, Bhayana S, Susnik N, et al (2015). Zinc- $\alpha 2-$ glycoprotein exerts antifibrotic effects in kidney and heart. J Am Soc Nephrol, 26, 2659-68.

Stanisavljević N, Bajić SS, Jovanović Ž, et al (2020). Antioxidant and antiproliferative activity of Allium ursinum and their associated microbiota during simulated in vitro digestion in the presence of food matrix. Front Microbiol, 11, 601616.

Stickel F, Schuppan D (2007). Herbal medicine in the treatment of liver diseases. Dig Liver Dis, 39, 293-304.

Sudhakar D, Krishna KR, Parthasarathy PR (2010). Portulaca oleracea $\mathrm{L}$. extract ameliorates the cisplatin induced toxicity in chick embryonic liver. Indian J Biochem Bio, 47, 185-9.

Supatutkul C, Pramchu S, Jaroenjittichai AP, et al (2017). Electronic properties of two-dimensional zinc oxide in hexagonal, $(4,4)$-tetragonal, and (4, 8)-tetragonal structures by using Hybrid Functional calculation. $J$ Phys Conf Ser, 901, 012172.

Suvarna KS, Layton C, Bancroft JD (2019). Bancroft's theory and practice of histological techniques. 8th ed. London, UK: Elsevier Ltd., p. 672.

Syafiuddin A, Salmiati, Salim MR, et al (2017). A Review of silver nanoparticles: Research trends, global consumption, synthesis, properties, and future Challenges. J Clin Chem Soc, 64, 732-56.

Szuster-Ciesielska A, Plewka K, Daniluk J, et al (2009). Zinc supplementation attenuates ethanol-and acetaldehydeinduced liver stellate cell activation by inhibiting reactive oxygen species (ROS) production and by influencing intracellular signaling. Biochem Pharmacol, 78, 301-14.

Talam S, Karumuri SR, Gunnam N (2012). Synthesis, characterization, and spectroscopic properties of $\mathrm{ZnO}$ nanoparticles. Int Scholarly Res Notices, 2012, Article ID 372505, 6 pages.

Tarantino G, Conca P, Pasanisi F, et al (2009). Could inflammatory markers help diagnose nonalcoholic Steatohepatities? Eur $J$ Gastroenterol Hepatol, 21, 504-11.

Thiruvengadam M, Chung I-M, Gomathi T, et al (2019). Synthesis, characterization and pharmacological potential of green synthesized copper nanoparticles. Bioprocess Biosyst Eng, 42, 1769-77.

Tsai MK, Lin YL, Huang YT (2010). Effects of salvianolic acids on oxidative stress and hepatic fibrosis in rats. Toxicol Appl Pharmacol, 242, 155-64.

Uddin MK, Juraimi AS, Hossain MS, et al (2014). Purslane Weed: A prospective plant source of nutrition, omega- 3 fatty acid and antioxidants. Sci World J, 2014, 1-6.

Vasudeo K, Pramod K (2016). Biosynthesis of nickel nanoparticles using leaf extract of coriander. Biotechnology, 12, $1-6$.

Vichai V, Kirtikara K (2006). Sulforhodamine B colorimetric assay for cytotoxicity screening. Nat Protocols, 1, 1112-6.

Wahab R, Siddiqui MA, Saquib Q, et al (2014). ZnO nanoparticles induced oxidative stress and apoptosis in HepG2 and MCF-7 cancer cells and their antibacterial activity. Colloids Surf B Biointerfaces, 117, 267-76.

Wang C, Lu J, Zhou L, et al (2016). Effects of long term exposure to zinc oxide nanoparticles on development, zinc metabolism and biodistribution of minerals $(\mathrm{Zn}, \mathrm{Fe}, \mathrm{Cu}, \mathrm{Mn})$ in mice. 
PLoS One, 11, 0164434.

Wang J, Deng X, Zhang F, et al (2014). ZnO nanoparticleinduced oxidative stress triggers apoptosis by activating JNK signaling pathway in cultured primary astrocytes. Nanoscale Res Lett, 9, 1-12.]

Wang Z, Zhao J, Li F, et al (2009). Adsorption and inhibition of acetylcholinesterase by different nanoparticles. Chemosphere, 77, 67-73.

Wickramaratne MN, Punchihewa J, Wickramaratne D (2016). In-vitro alpha amylase inhibitory activity of the leaf extracts of Adenanthera pavonina. BMC Complement Altern Med, 16, 466 .

Wynn TA (2008). Cellular and molecular mechanisms of fibrosis. J Pathol, 214, 199-210.

Xia C, Liu Y, Chen Z, et al (2015). Involvement of interleukin 6 in hepatitis B viral infection. Cell Physiol Biochem, 37, 677-86.

Yang H, Liu C, Yang D, et al (2009). Comparative study of cytotoxicity, oxidative stress and genotoxicity induced by four typical nanomaterials: the role of particle size, shape and composition. J Appl Toxicol, 29, 69-78.

Yang HY, Kim KS, Lee YH, et al (2019). Dendropanax morbifera ameliorates thioacetamide-induced hepatic fibrosis via TGFbeta1/smads pathways. Int J Biol Sci, 15, 800-11.

Yen SC, Mashitah MD (2013). Optimization of process variables for the synthesis of silver nanoparticles by Pycnoporus sanguineus using statistical experimental design. J Korean Soc Appl Biol Chem, 56, 11-20.

Youssef AM, Abdel-Aziz MS, El-Sayed SM (2014). Chitosan nanocomposite films based on Ag-NP and Au-NP biosynthesis by Bacillus subtilis as packaging materials. Int J Biol Macromol, 69, 185-91.

\section{(ब) $\odot \otimes$}

This work is licensed under a Creative Commons AttributionNon Commercial 4.0 International License. 